\title{
Noise Measurements of a Low-Noise Top-Mounted Propulsion Installation for a supersonic airliner
}

\author{
JAMES BRIDGES \\ NASA Glenn Research Center, Cleveland, OH 44135
}

\begin{abstract}
A model-scale exhaust system was tested to validate low-noise concepts and noise prediction methods. The tests acquired far-field acoustics, acoustic source distributions, and turbulent velocity statistics; this report covers the far-field acoustic measurements. Data were acquired for a series of nozzles with different chevron designs, both uninstalled and installed on a representative aircraft planform. The impact of the various chevron treatments on the far-field noise was documented, along with the impact of the pylon and planform. For the baseline nozzle, installation produced a 2EPNdB reduction, as was assumed in system studies. Chevrons were used to shift noise sources upstream to maximize the installation benefits and to reduce unshielded sources downstream. These resulted in reductions of 4-5EPNdB relative to the uninstalled baseline nozzle. Detailed analysis of spectral directivities behind the integrated EPNL metric gave insight into how well these concepts actually work. When correlated with particle image velocimetry measurements and phased array measurements, reported in companion papers, the explanation of acoustic benefits from top-mounted propulsion is clear, as is the path toward optimization of the concept.
\end{abstract}

\section{Nomenclature}

EPNLEffective Perceived Noise Level

IVP Inverted Velocity Profile

$M_{\star} \quad$ flight Mach number

$N P R p$ nozzle pressure ratio of primary stream

NPRf nozzle pressure ratio of fan streams

$P S D$ power spectral density of sound pressure

\section{Introduction}

NASA has been studying the viability of civilian supersonic airliners for some time ${ }^{12}$. In recent testing a greater acoustic effect was found from installation than from nozzle type for a given engine. In the concept vehicle studied, one engine (center) was mounted above the aft deck of the aircraft while two engines (outboard) were mounted below. The propulsion system mounted on the top of the aircraft had substantial (2-3EPNdB) shielding of mixing noise in the frequency range of human annoyance. The propulsion mounted under the aircraft body experienced substantial increase (again 2-3EPNdB) in the mixing noise due to reflection of this noise from the underside of the aircraft. Based on this, NASA has explored the noise reduction that could be obtained by moving the outboard propulsion to the top of the concept vehicle, estimating the possible acoustic advantages and aerodynamic impacts on range and sonic boom. The results were promising, greatly reducing jet mixing noise and removing fan noise as a contributor to certification noise, much as has been found in previous studies of subsonic aircraft ${ }^{45}$. The aerodynamic penalties for top-mounted propulsion are still significant, hence every effort must be made to maximize the noise benefits of this installation.

The noise-modifying characteristics of chevrons and other mixing enhancement devices are fairly well-known ${ }^{65}$. These increase turbulent mixing near the nozzle, reducing the jet velocity and turbulence downstream. This has been used to reduce the peak, low-frequency jet noise directed at aft angles. However, the enhanced mixing increases the high frequency sound, which is at peak annoyance to humans, as the increased turbulent mixing energy close to the

Acoustics Branch, M/S 54-3; AIAA Associate Fellow 
nozzle creates more noise. Balancing the benefit of reducing the low and enhancing the high frequencies to minimize human annoyance has been the challenge of designing such nozzles. Given that enhanced mixing usually decreases thrust further adds to the difficulty.

Installation changes the design rules for optimizing chevronss. When the enhanced-mixing nozzle is mounted on the top of the vehicle, the enhanced high frequencies can be shielded from the observer while the uncovered low frequencies downstream will be reduced. The result is a strong reduction in annoyance to the observer, if the mixing is brought far enough upstream and the noise adequately shielded. The key is accurately predicting the distribution of noise sources ${ }^{\circ}$ at different frequencies to produce the maximum benefit, while maintaining adequate thrust.

To explore this concept, a simplified acoustic analogy code for predicting jet noise was employed on an exhaust system studied previously with conventional, underbody installations. The previous concept aircraft was reimagined with all top-mounted propulsion as shown in Figure 1. Chevron nozzles were designed that shifted the noise sources upstream to obtain greater suppression than the unenhanced, baseline nozzle. The previously tested inverted velocity profile exhaust system, featuring a tertiary stream over a $180^{\circ}$ annulus, was used as the baseline nozzle. Chevrons were designed to augment mixing between the primary and flight streams, between the primary and tertiary streams, and between the tertiary and flight streams. A planform representation of the airframe was created to mimic the installation of the propulsion units on the top of the vehicle. Combinations of the nozzle, chevrons, and planform allowed evaluation of system-level estimates of noise reduction for the installation of the baseline nozzle, and exploration of the additional benefits of modifying noise source distributions.

The tests were also planned with validation of jet flow and noise prediction methods in mind. Modern jet noise prediction methods require that the turbulent plume of the jet be properly predicted as a precursor to prediction of its sound. Measurements of the turbulent velocity fields $s^{10}$ and of noise source distributions" of the jet are presented in companion papers, and work done to predict the flow and noise of these configurations from Reynolds-Averaged Navier-Stokes simulations ${ }^{2}$ is also reported in this conference.

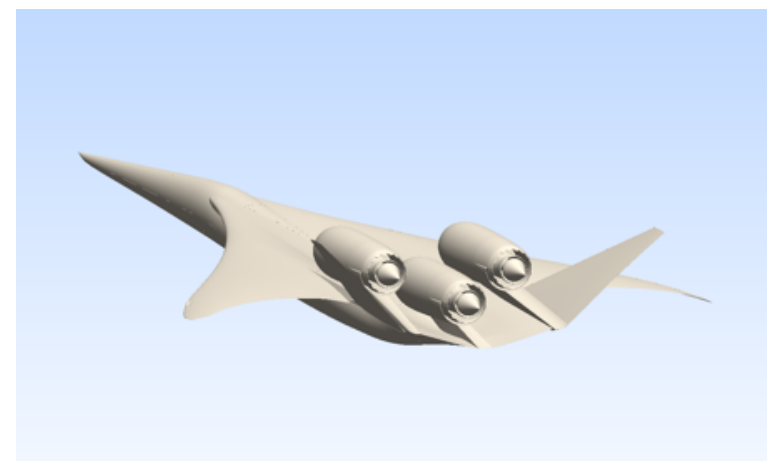

Figure 1. Concept aircraft, modified for three top-mounted, podded engines.

\section{Facility and Instrumentation}

The test was conducted in the NASA Glenn Research Center Aero-Acoustic Propulsion Laboratory (AAPL). The AAPL is a 20m-radius anechoic geodesic hemispherical dome. Acoustic wedges cover the walls of the dome and approximately half of the floor area. The AAPL was acoustically clean for all acoustic test runs, with acoustic wedges on the front and microphone sides of all surfaces of the facility. The ambient temperature, pressure, and relative humidity were recorded within the dome during each data acquisition and used to transform the data to that of a flight at a standard day.

The Nozzle Aeroacoustic Test Rig (NATR) was contained in the AAPL. The NATR provided the flight stream for the jet rig. The NATR ductwork was acoustically lined on both the inside and outside and consisted of an annular ejector system connected to a plenum followed by the transition section which was an ASME long-radius, low-beta venturi nozzle. This flow was exhausted through a $1.35 \mathrm{~m}$-diameter nozzle to form a free jet to simulate the effects of forward flight on the test article. The centerline of the free jet was $3 \mathrm{~m}$ above the floor. An acoustically treated wall separates the NATR from the section of the building which did not have acoustic treatment on the floor, preventing unwanted reflections from the both the untreated floor area and adjacent test equipment. 
The High Flow Jet Exit Rig (HFJER), located at the downstream end of the NATR, is the structure through which heated air was delivered from the facility compressed air system to the test article. The HFJER is effectively a turbofan engine simulator. The first air stream was heated using a natural gas combustor. The second air stream was heated using a heat exchanger. For this test, HFJER was fitted with a third annular stream of air to feed three-stream, variable cycle nozzles. This third stream, which was diverted from the usual second stream prior to its control valve, was independently controlled for pressure but had roughly the same temperature as the second stream.

The rig was fitted with rotating collar section downstream of the third-stream plenum. A support arm cantilevered downstream from the outer rotating spool of the rotating collar section to support the model planforms and allow them to be positioned at multiple azimuthal angles. Next on the stack was a stream inverter that ducted the second annular airstream into the center of the nozzle system, producing the inverted velocity profile (IVP) capability. The nozzle model hardware, described below in detail, attached to this stream inverter. Rotations of the model system, both nozzle and planform, were relative to the far-field array, $\sim 30^{\circ}$ from vertical in AAPL.

The parts of the jet rig and model system are identified in Figure 2. Figure 3 is a photo of the fully built up rig with an isolated nozzle installed.

The rig was instrumented to record total temperature, total pressure at the charging station on all streams, including the IVP-specific instrumentation in the cold stream of the inner flow path. In addition, mass flowrates were recorded using flow venturi. Ambient conditions were recorded on the facility computer, along with all rig instrumentation, at a $1 \mathrm{~Hz}$ sample rate during periods of acoustic data acquisition. Relative humidity and temperature were recorded both at $3 \mathrm{~m}$ above the floor near the NATR and at the top-most region of the overhead microphone array, located roughly $18 \mathrm{~m}$ above the floor. Ambient pressure was recorded in a sheltered location within the dome.

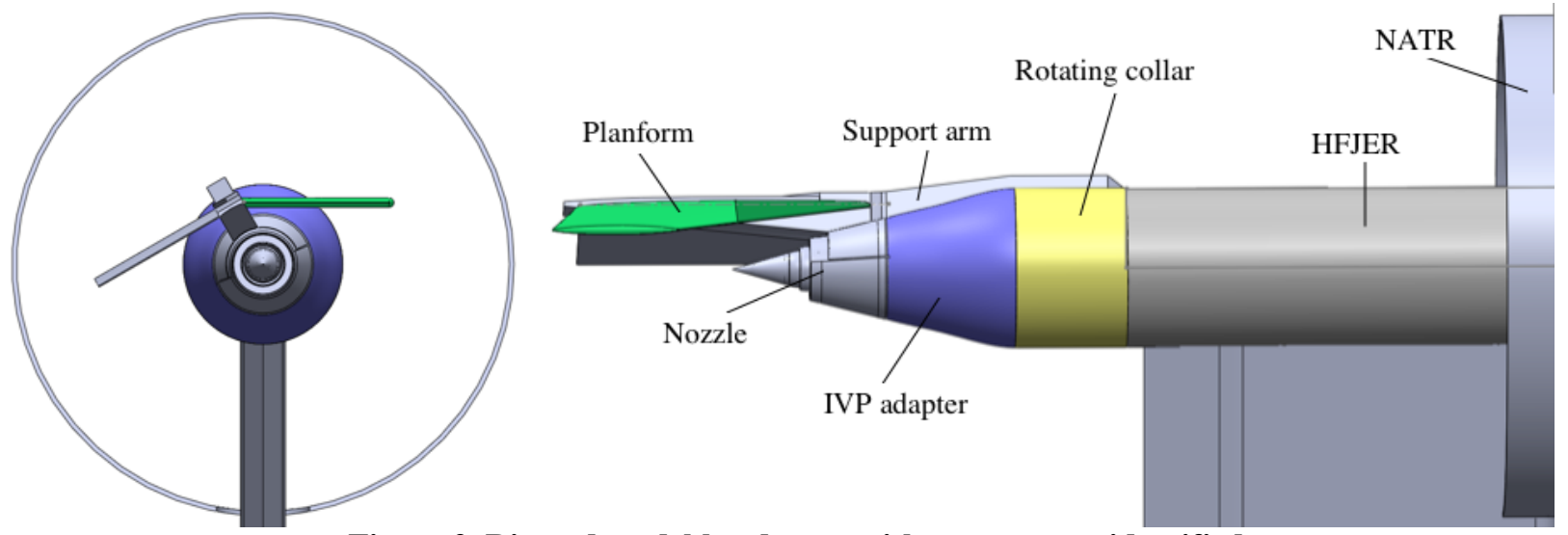

Figure 2. Rig and model hardware, with components identified.

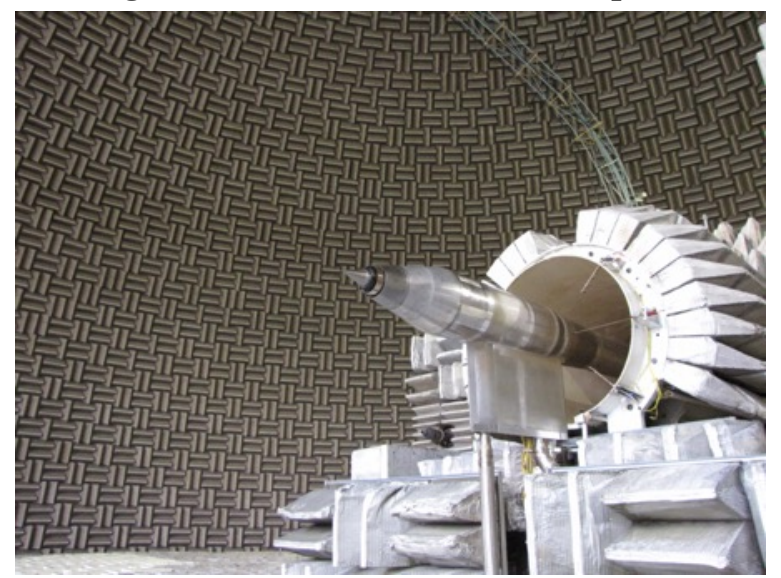

Figure 3. HFJER with third-stream plenum, rotating collar, and inverted velocity profile adapter installed in NATR with overhead microphone array shown in background.

An overhead array of 24 microphones was used to measure far-field spectral directivity. The arc of microphones had a radius of $13.5 \mathrm{~m}$, and was centered at a point on the jet axis roughly $2 \mathrm{~m}$ upstream of the nozzle exit, or at the exit 
plane of the NATR. The microphones were installed without gridcaps on $1 \mathrm{~m}$ stingers off carts spaced roughly $5^{\circ}$ apart on an overhead track, as shown in the background of Figure 3, and were oriented normal to the jet exit. Transformed to the nozzle coordinate system the microphones covered a span of polar angles $40^{\circ}$ to $156^{\circ}$ from the upstream axis. The 1/4" microphones were Bruel \&Kjaer 4939 condenser microphones with 1/4" Bruel \&Kjaer preamps powered by Bruel \&Kjaer Nexus power supply/signal conditioners. Microphones were factory-calibrated prior to the test. End-toend insitu calibrations of the microphones were performed weekly using a Bruel \&Kjaer pistonphone.

Acoustic time records were acquired on a DataMAX acquisition computer and processed on a Linux computer using the in-house Digital Acoustic Data System (DADS). When the facility instrumentation indicated that the flow conditions were within $0.5 \%$ total error of the designated setpoint, 10 seconds of acoustic data were acquired along with a 10 -second average of all rig instrumentation. Acoustic data were processed to account for individual microphone sensitivity and spectral characteristics, losses due to atmospheric attenuation between the jet and the microphone, and spherical spreading. During correction for refraction through the flight stream shear layer ${ }^{3}$, the microphone angles shifted, allowing interpolation onto a common set of angles from $45^{\circ}$ to $160^{\circ}$.

For EPNL calculations, the model-scale data were scaled to that of a full-size nozzle (scale factor 9:1). The data were propagated to an observer at a sideline distance of $544 \mathrm{~m}$ using spherical spreading without ground effects but including Doppler effects and atmospheric absorption for a standard day. To match earlier studies, the data were processed for a flight speed of $\mathrm{M}_{*}=0.38$ and the source strength slightly adjusted to account for the difference from the flight speed of the experiment $\left(\mathrm{M}_{*}=0.35\right)$.

\section{Model Hardware}

\section{A. Model hardware configurations}

The installed exhaust concepts being evaluated in this test program consisted of nozzles installed above aft decks of the aircraft with variations in an enhanced mixer to shift the noise sources further upstream for increased shielding.

Nozzle: The baseline nozzle had three streams and an external plug. The inner annulus was axisymmetric and thin, carrying approximately half the flow generated by the three-stream engines' tip fan. The second annulus was the primary stream, passing the core and primary fan streams which would be fully mixed upstream in the conceptual engine. It was also axisymmetric. The tertiary nozzle carries the other half of the tip fan flow, and was an annulus that covers roughly half of the circumference of the nozzle. This tertiary stream makes the plume bisymmetric, and requires a notation as to whether the observer was on the side facing the tertiary stream, noted as 'A0', or away from it, noted as 'A 180 '. The total nozzle area was $0.0165 \mathrm{~m}$ ', with a primary nozzle diameter of $170 \mathrm{~mm}$.

Chevrons: For the mixing enhancement, the nozzles used chevrons, with varying location and penetration. These chevrons were intentionally aggressive in their penetration because they were to be installed where much of the noise produced by enhanced mixing would be shielded. Chevrons were separately applied to a $180^{\circ}$ arc of the primary nozzle lip, either over the tertiary and flight stream sides of the primary nozzle. The nomenclature of these locations is given in Figure 4. Two chevron designs, varying the penetration of the chevrons, was used on each side. The two designs were approximately the same on each side, with a set of lower penetration chevrons having an angle $\sim 10^{\circ}$ to the centerline, and a higher penetration design having an angle of $\sim 16^{\circ}$ to the centerline. Table 1 gives the naming convention for the different chevrons.
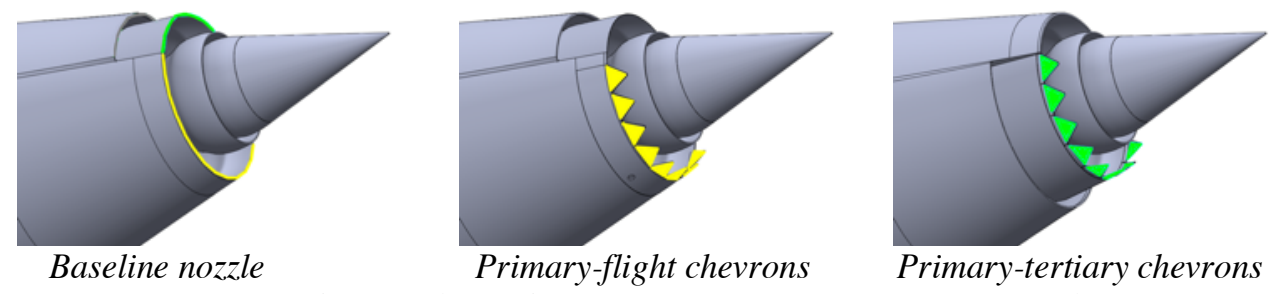

Figure 4. Nomenclature for locations of chevrons. Note that exhaust system is rotated between views.

Pylons: Two different pylon designs were tested, primarily differing in their standoff and to which nozzle lip they mated. The two different pylon standoffs are shown in Figure 5. The 'J' planform was the same pylon that was used for the underwing engine installation in an earlier test, but with the tailfin rotated upwards to simulate the top-mounting position. This had a very shallow standoff and only fit on the side of the primary nozzle exposed to the flight stream. More realistically, when the outboard engines were rotated to the topside of the aircraft planform, they must be raised 
up so that the inlets clear the body of the aircraft. This creates the standoff given by the new planform, designated ' $T$ '. This pylon mates to the tertiary nozzle, as it was expected that having the low-speed tertiary flow on the observer side of the nozzle would produce the most benefit to the observer by lowering the convection speed of turbulence on that side of the jet.

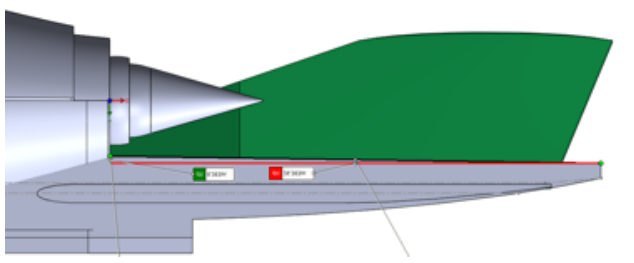

$\begin{array}{rc}\text { Planform } & J \\ \text { Length }[\mathrm{mm}] & 668 \\ \text { Standoff }[\mathrm{mm}] & 10\end{array}$

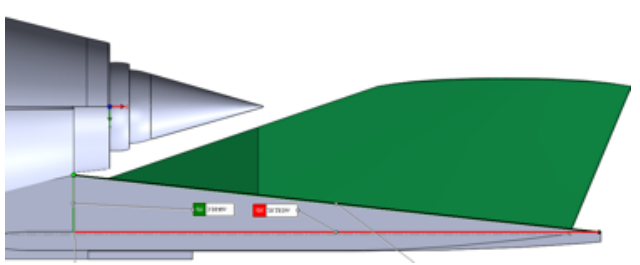

$\begin{array}{rc}\text { Planform } & T \\ \text { Length [mm] } & 715 \\ \text { Standoff }[\mathrm{mm}] & 78\end{array}$

Figure 5. Dimensions of pylons ' $J$ '(top) and T' (bottom).

Table 1. Hardware components to comprise model configuration

\begin{tabular}{|c|l|}
\hline Component code & Description \\
\hline \multicolumn{2}{|c|}{ Primary-flight lip $(X)$} \\
\hline 0 & Baseline lip \\
1 & $10^{\circ}$ chevron \\
2 & $16^{\circ}$ chevron \\
\hline \multicolumn{2}{|c|}{ Primary-tertiary lip $(Y)$} \\
\hline 0 & Baseline lip \\
3 & $10^{\circ}$ chevron \\
4 & $16^{\circ}$ chevron \\
\hline \multicolumn{3}{|c|}{ Planforms $(Z)$} \\
B & No planform \\
J & Low standoff \\
T & High standoff \\
\hline
\end{tabular}

Observer orientations: For the uninstalled configurations, the azimuthal orientation of the tertiary stream relative to the plane of the microphones could be changed by rotating the nozzle. When the tertiary stream was on the side toward the microphones, the configuration was noted as ' $\mathrm{A} 0$ '; when the tertiary stream was away from the microphones, the configuration was noted as 'A180'.

To evaluate the installed noise of an aircraft, polar arcs in two azimuthal planes were measured, corresponding to the flyover and lateral certification observers. This required both nozzle and planform to be rotated relative to the microphones. The designation 'SO' indicates that the planform was positioned for the microphone array to be directly under the aircraft. The designation 'S60' indicates that the planform was rotated such that the microphones were in a polar plane at an azimuthal angle $60^{\circ}$ from under the aircraft, corresponding to the lateral observer in certification tests.

In summary, the model hardware available for this test consisted of three nearly independent parameters: azimuthal location of chevrons, penetration of those chevrons, and the planform. The matrix of chevron and pylon parameters is given in Table 1. A configuration code was developed to describe configurations: $X Y 0 Z$, where $X, Y, Z$ are numerical values for the chevron designs from Table 1. 


\section{Flow conditions}

The flow conditions were defined from cycles studied under the NASA Low-Noise/Low-Boom Tech Challenge ${ }^{2}$. A three-stream (tip-fan) engine was defined that, when installed on a concept supersonic aircraft, met the ICAO Chapter 14 airport noise regulations when programmed lapse rate was implemented. The inverted velocity profile nozzle achieved an acceptable level when installed in the two-below, one-above configuration with the engines running at a primary nozzle pressure ratio $\left(N P R_{r}\right)$ of 1.86 . For this test, the cycle was defined over the $N P R_{r}$ range from 1.4 to 2.6 to see where the new installed nozzle would hit this single-engine EPNL. In the conceptual engine, the primary stream of the nozzle was fed by mixing the core and main fan streams internally, producing a mixed primary temperature around $560 \mathrm{~K}$ at a pressure ratio of 2 , and the tertiary fan stream, split between the innermost and tertiary nozzle passages was operating at a pressure ratio $N P R=1.8$ and temperature of $360 \mathrm{~K}$. Engine conditions on a throttle line below and above this flow condition, with $N P R_{p}=1.8$ and 2.3, were also tested. The flight stream was $M=0.3$ for all test points. The data were transformed to $M=0.38$ using procedures documented in previous tests ${ }^{3}$ for EPNL analysis.

\section{Results}

The far-field acoustic results of the test will first address the acoustic effect of the various chevron designs, uninstalled. Then results will be given showing how installation on the aircraft planform changed the total noise of the propulsion system. In each section, results are first summarized by EPNL over the engine cycle, and then explored in detail using carpet plots of spectral directivity, and delta-dB changes in power spectral density (PSD) between configurations.

All spectral directivities shown here are given as power spectral density (PSD) as a function of frequency and polar angle with the origin in the flight direction. The PSD are in model scale, transformed to a 1 -foot $(0.305 \mathrm{~m})$, lossless observer scenario. All EPNL values were calculated for a single engine, scaled to fullscale, and flown at $M=0.38$ at a distance of $544 \mathrm{~m}$ from the observer. This distance was roughly that of the lateral observer, but was used for consistency even when the azimuthal angle of the observer was directly under the aircraft.

\section{A. Baseline configuration}

The far-field directivity of the baseline nozzle has a few peculiarities to note before the impact of chevrons and installation are presented. As noted in previous tests of this nozzle flows to curve strongly over the plug (inner stream) and over the inner nozzle (primary stream). This causes the flow to have acceleration-induced shocks on the nozzle which appear to produce a noise source which resembles broadband shock noise in frequency and directivity. The $180^{\circ}$ tertiary flow modifies this source, producing a spectral difference in the sound directed towards observers on the two different sides of the nozzle.

The EPNL over the power cycle, delineated by the pressure ratio of the primary nozzle, $N P R_{r}$, is given in Figure 6 for the uninstalled baseline nozzle $(000 \mathrm{~B})$. The main azimuthal difference, produced by the asymmetry of the nozzle, was in the middle of the power cycle, around $N P R_{r}=2.0$, where the A180 side (away from tertiary nozzle) exceeds the A0 side by $1 \mathrm{EPNdB}$. Otherwise, the noise was nearly symmetric.

Determining the reason for the directional difference starts by looking at the spectra of the far-field noise as a function of polar angle in the two azimuthal directions. These spectral directivities of the uninstalled baseline nozzle are presented in Figure 7. The spectra look like standard jet noise with a few notable exceptions. First, there was a succession of spectral humps starting at low angles around $10 \mathrm{kHz}(\log 10(\mathrm{~Hz})=4)$ and increasing slightly in frequency with increasing polar angle. In previous tests of this nozzle, this feature was explored in detail, where it was determined that it was a feature of the jet and not a reflection from a microphone holder or a noise source internal to the model. The change in frequency of this feature with polar angle, inverse that of a Doppler shift, was reminiscent of broadband shock noise. The current understanding is that this noise was being created by the shocks produced by the curvature of the nozzle flow over the plug and cowl. Second, this spectral hump changes character with NPRp, having one shape below $N P R_{r}=2$, where it nearly disappears. It then comes back with increase in $N P R_{r}$, but with a different spectral character, having fewer humps at a given forward polar angle. The broadband shock feature, both below and above $N P R_{p}=2$, was nearly the same on both azimuthal planes. However, the reduction of the hump at $N P R_{p}=2$ was enough different on the two sides of the nozzle to make a difference in the EPNL.

Being oriented to the spectral character of the baseline, uninstalled nozzle, next consider the impacts made by the addition of chevrons and by installation. 


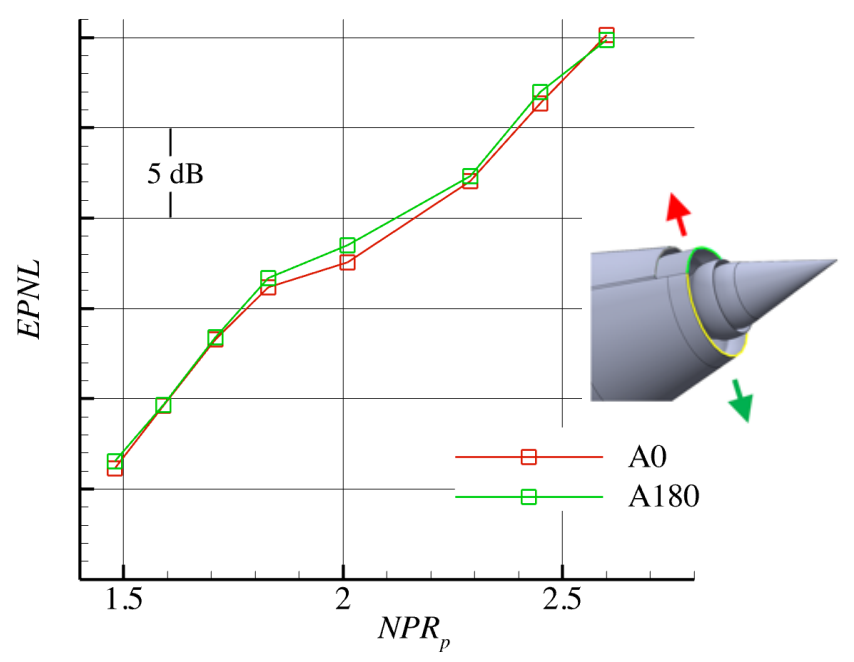

Figure 6. EPNL of baseline, nozzle with no planform. Azimuthal differences, tertiary nozzle toward observer (A0) and away from observer (A180).

(a)
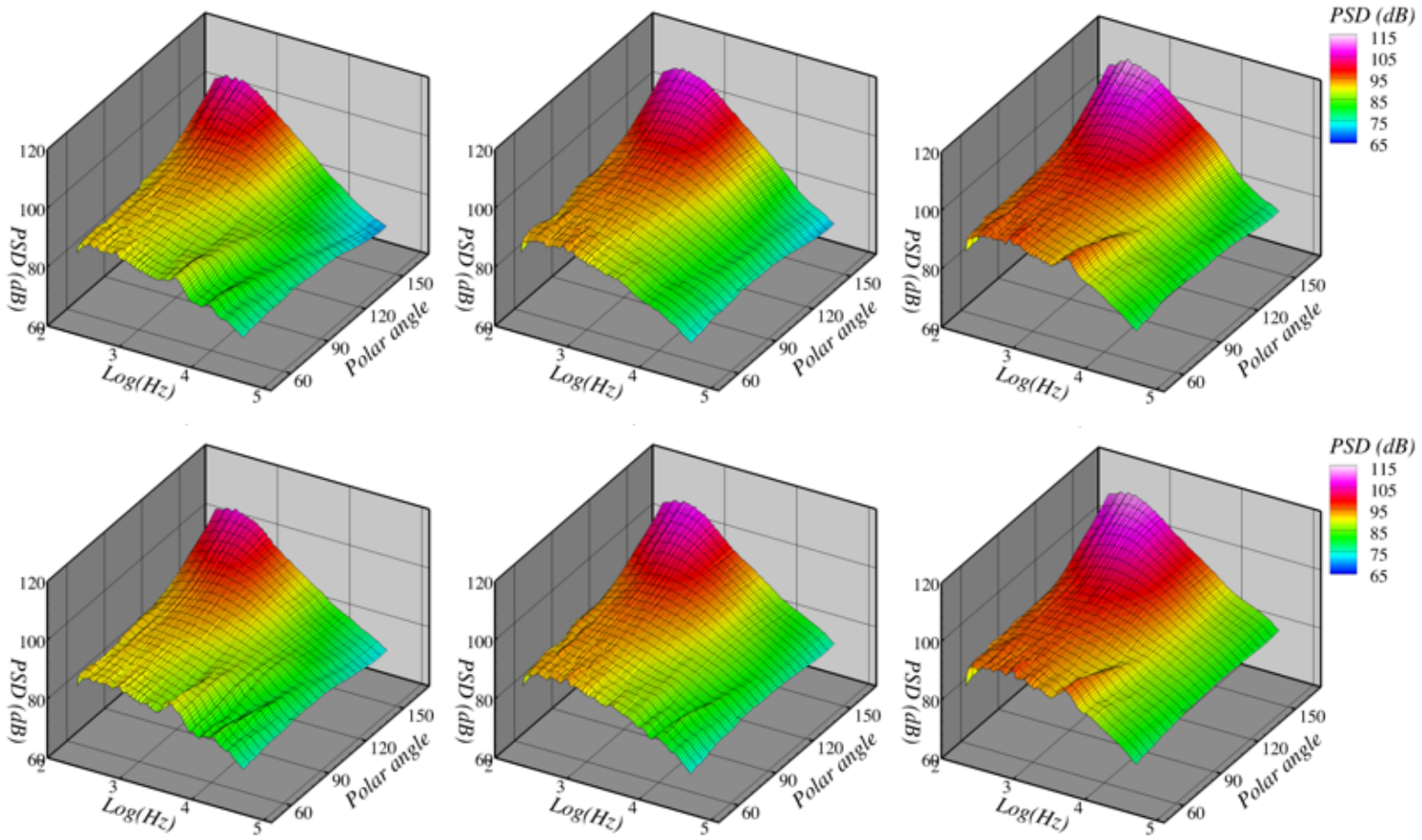

$N P R_{p}=1.8$

$N P R_{p}=2$

$N P R_{p}=2.3$

Figure 7. Spectral directivity of baseline nozzle, isolated (000B), rotated with tertiary stream (a) toward observer (A0) and (b) away from observer (A180) for three flow setpoints.

\section{B. Trends in noise of chevron designs, uninstalled.}

Key to the concept of redistributing and shielding noise sources is the use of mixing enhancement features on the nozzle. In this test, the mixing enhancement devices were chevrons, positioned on nozzle lips between different streams and having variable penetration, as given in Table 1 . The penetrations of chevrons 1 and 3 were the same, as were chevrons 2 and 4. Because each chevron design was only applied to one half of the nozzle, there was the additional parameter of whether the chevrons were on the observer side or opposite it. In the plots below, the azimuthal orientation is given as to whether the tertiary nozzle was toward the observer (A0) or away (A180). Chevrons on the primary nozzle exposed to the ambient flight stream were identified by the first character of the configuration code as 
either 1 or 2 (or 0 for no chevron). Chevrons on the primary nozzle exposed to the tertiary stream were identified as either 3 or 4 (or 0 for no chevron). Small graphics are given on the figures to assist in configuration identification.

Figure 8 presents the EPNL over the engine cycle for the flight-stream chevrons with the observer positioned on the side of the nozzle with the tertiary nozzle (A0). For this chevron location, the observer was on the side away from the chevrons. At the highest and lowest $N P R_{p}$ the chevrons make no difference in the EPNL. At mid values of $N P R_{\nu}$ the chevrons had a total noise penalty, which was greater for the more aggressive chevron. The penalty was worst at $N P R_{p}$ $=2.3$, where the $200 \mathrm{~B}$ configuration was $2 \mathrm{EPNdB}$ louder than the baseline.

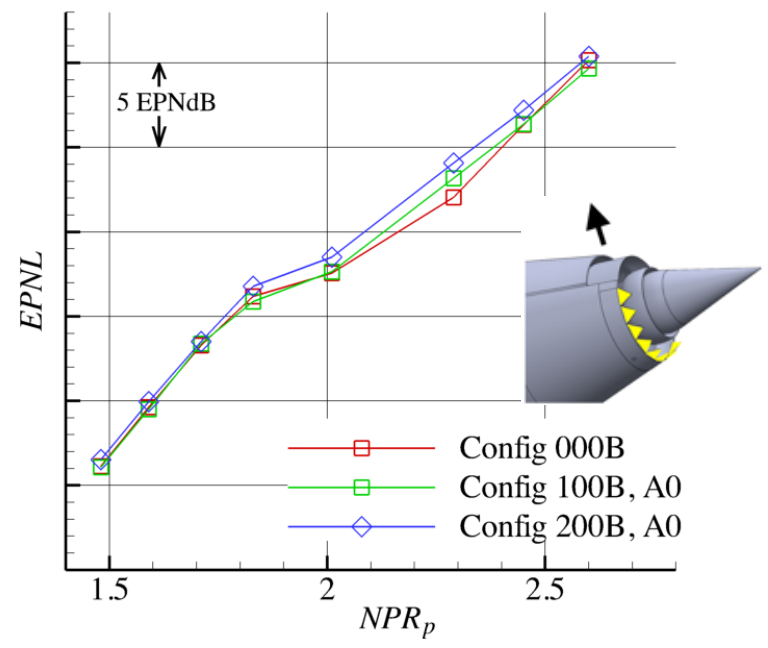

Figure 8. Single-engine EPNL of uninstalled chevron nozzles with varying penetrations mounted on primary-flight lip. Observer on tertiary nozzle side, away from chevrons.

The change in spectral directivity behind these changes in EPNL are shown in Figure 9. In this figure, the shape of the surface plots are the spectral directivity of the uninstalled chevron nozzles operating at $N P R_{r}=2.0$, while the color contours give the difference in PSD from that of the baseline nozzle. The red colors at the high frequencies show how the low-penetration chevrons (100B) increased the high frequency noise by $2 \mathrm{~dB}$, while reducing the low frequencies by $2 \mathrm{~dB}$. The high-penetration chevrons (200B) increased it by $3 \mathrm{~dB}$.

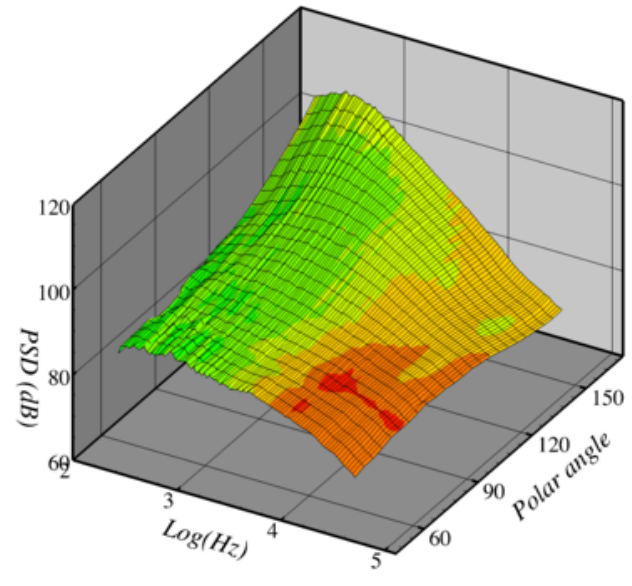

(a)

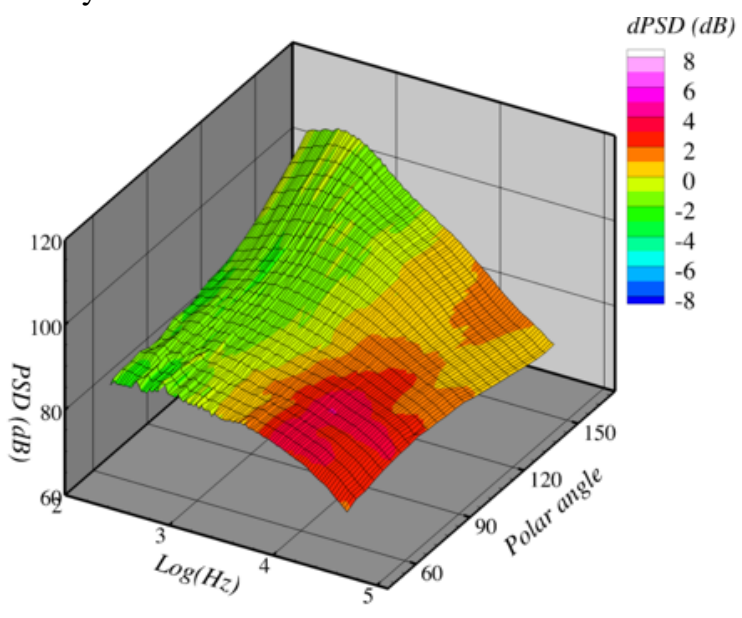

(b)

Figure 9. Spectral directivity of uninstalled chevron nozzles, observer on opposite side from chevrons. Color indicates difference from baseline nozzle at $N P R_{p}=2.0$. (a) low-penetration chevron 100B, (b) highpenetration chevron 200B.

The noise of the chevron nozzles was not axisymmetric - it matters whether the chevrons were facing the observer or away from the observer. When the observer was on the side facing the chevrons, the EPNL penalty gets worse. Figure 10 shows the same EPNL vs $N P R_{p}$ as Figure 8, but substitutes the data from the 200B nozzle with data from 
the 100B nozzle acquired from the side facing the chevrons. On the chevron side, the EPNL was 2-4EPNdB higher than the non-chevron side and the baseline.

Looking at the spectral directivity change caused by the chevrons, there was a significant difference in the two sides. Figure 11 compares the noise produced on the two sides of the $100 \mathrm{~B}$ nozzle at $N P R_{p}=2.0$, with color contours giving the difference in noise relative to the baseline nozzle 000B. Both have similar $2 \mathrm{~dB}$ reductions at low frequencies, but at high frequencies the side facing the chevrons has $6 \mathrm{~dB}$ increase with chevrons, compared to no increase when the chevrons were on the side opposite the observer. There isn't as much difference between the two sides at the forward angles.

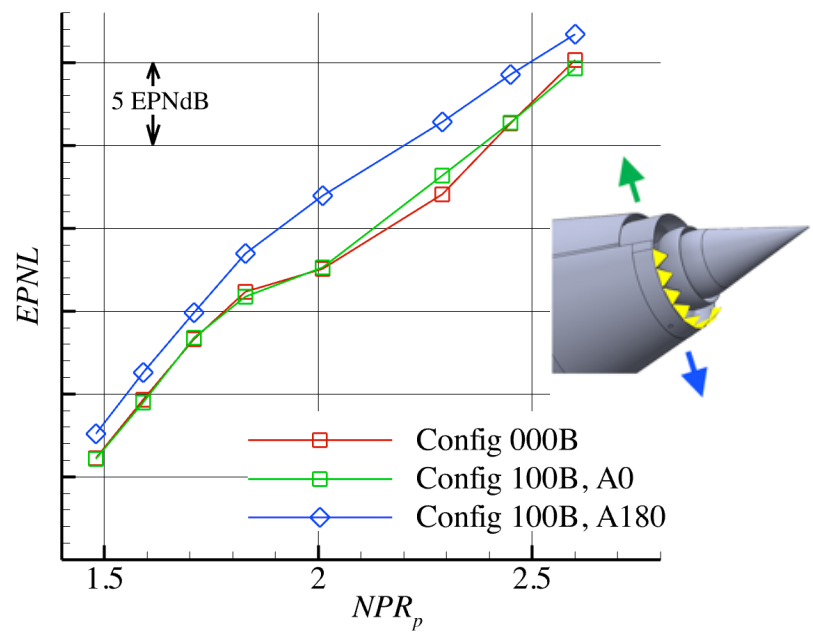

Figure 10. Single-engine EPNL of uninstalled chevron nozzle 100B with low-penetration chevrons mounted on primary-flight lip. Observer on sides toward (A0) and away (A180) from tertiary nozzle.

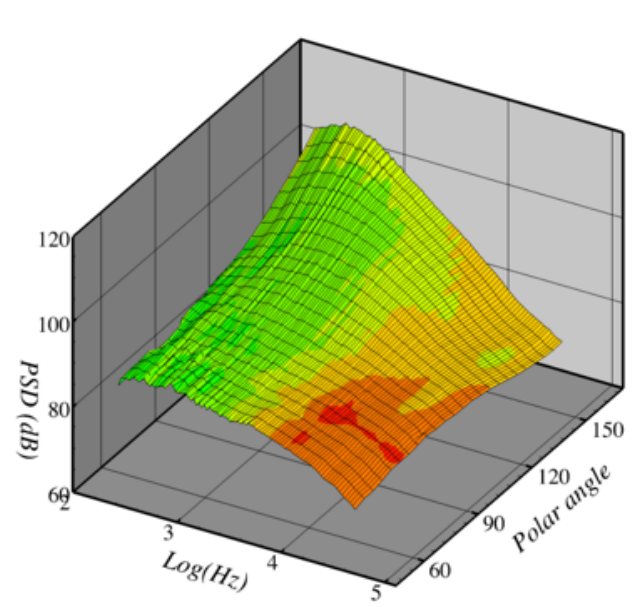

(a)

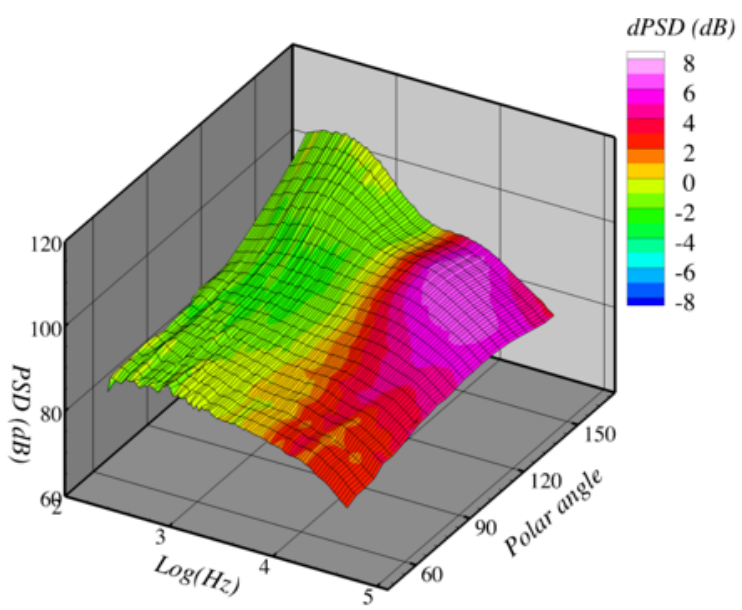

(b)

Figure 11. Spectral directivity of uninstalled chevron nozzle at $N P R_{p}=2.0$. Low-penetration chevrons installed between the primary and flight streams (nozzle 100), chevrons on side facing (a) away from observer and (b) toward observer. Color indicates difference with baseline nozzle.

Next, consider the impact of chevrons on the primary-tertiary nozzle lip, the 030B and 040B configurations, nozzles with the chevrons positioned on the primary lip in the arc between the primary and tertiary streams. Figure 12 gives the EPNL vs $N P R_{p}$ plot for the two chevron designs in this position, with the observer positioned on the side of the nozzle with the tertiary nozzle (A0), now being the same side as the chevrons. The impact of the chevrons was again to increase the EPNL levels, and again the higher penetration chevron was worse. Spectrally (Figure 13), both chevron designs produced similar low-frequency reductions of $2 \mathrm{~dB}$. Spatially, the two designs also produced similar increases at high frequency, predominantly toward the aft angles, but the higher penetration chevrons had peak increases of $8 \mathrm{~dB}$, where the low-penetration chevron peak increase was $5 \mathrm{~dB}$. 


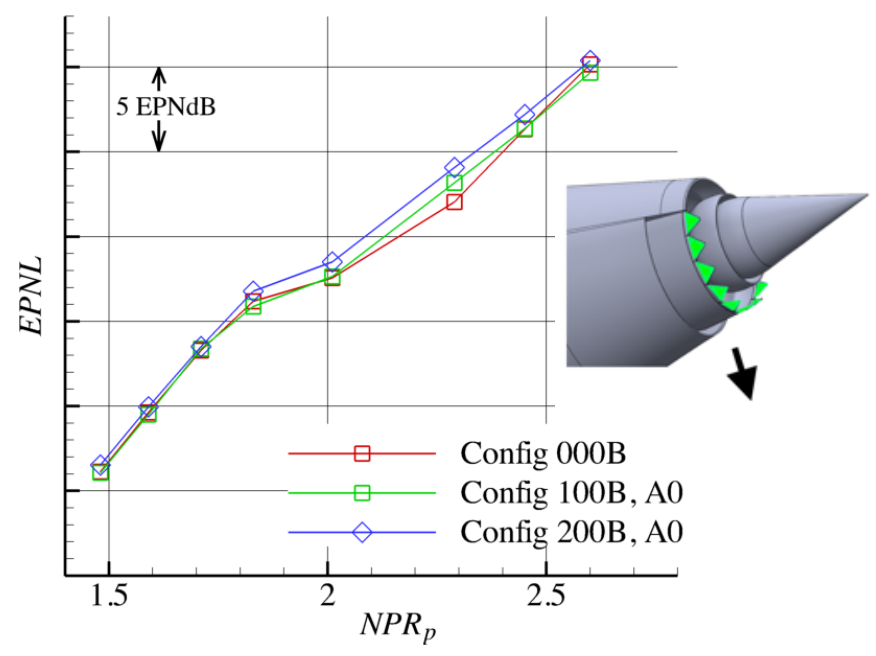

Figure 12. Single-engine EPNL of uninstalled chevron nozzles with varying penetrations mounted on primary-tertiary lip. Observer on tertiary nozzle side, toward chevrons

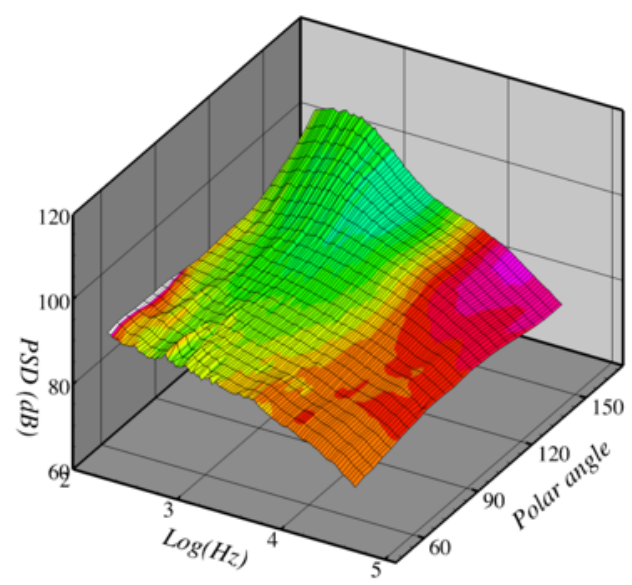

(a)

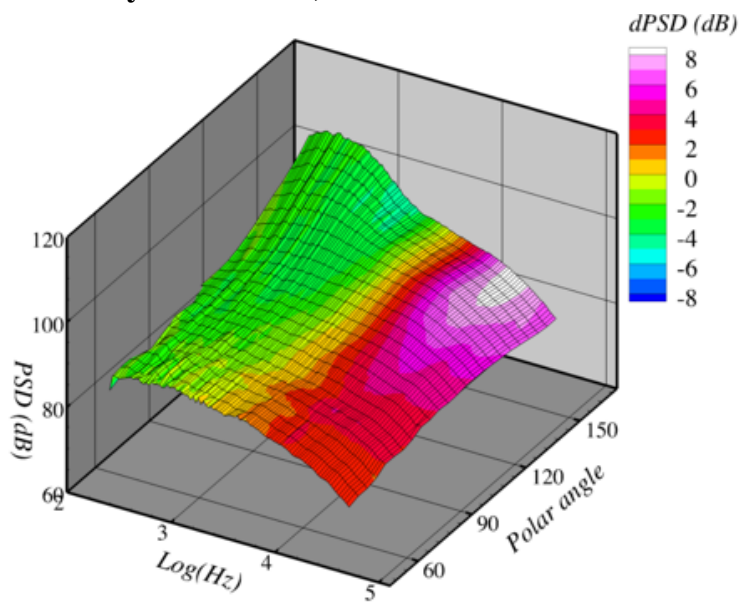

(b)

Figure 13. Spectral directivity of uninstalled chevron nozzles at $N P R_{p}=\mathbf{2 . 0}$, observer on same side as chevrons. Color indicates difference from baseline nozzle. (a) low-penetration chevron 030B, (b) highpenetration chevron $040 \mathrm{~B}$.

For chevrons between the flight and tertiary streams, the sound field was also not axisymmetric. Figure 14 presents the EPNL vs $N P R_{r}$ for the high-penetration chevron on the primary-flight lip as observed on opposite sides of the nozzle. The side away from the chevrons was lower than the side toward them, and both were louder than the baseline nozzle. Spectrally, the difference was entirely at high frequencies (Figure 15), and primarily at aft angles, where the chevron-exposed observer sees $3 \mathrm{~dB}$ more noise than the observer on the side opposite the chevrons. 


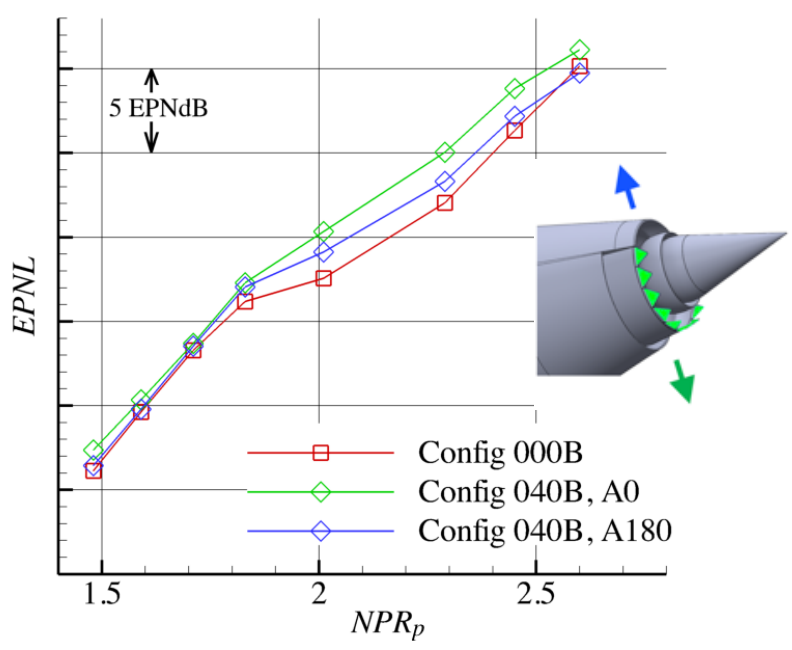

Figure 14. Single-engine EPNL of uninstalled chevron nozzle 040B with high-penetration chevrons mounted on primary-tertiary lip. Observer on sides toward (A0) and away (A180) from tertiary nozzle.

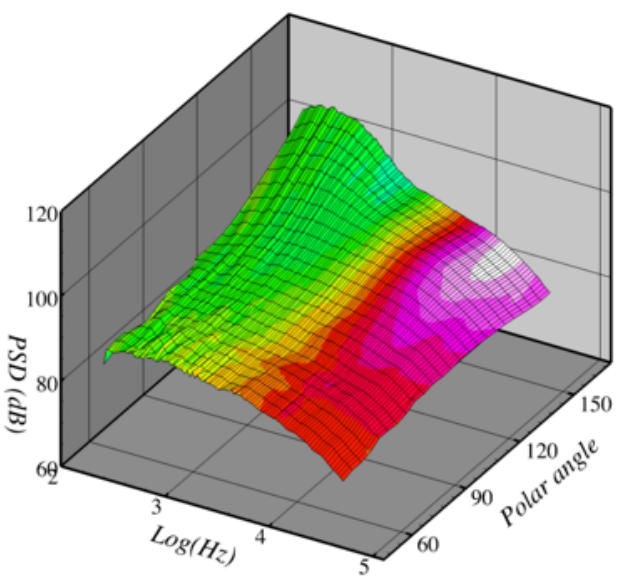

(a)

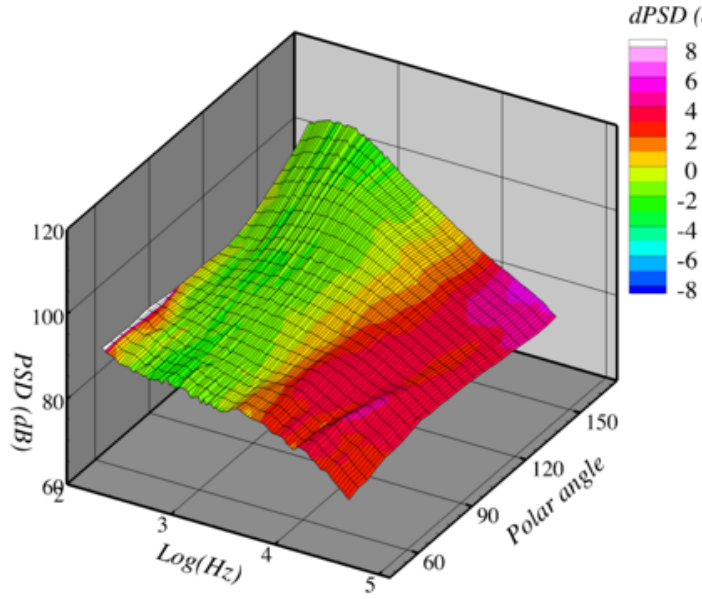

(b)

Figure 15. Spectral directivity of uninstalled chevron nozzle at $N P R_{r}=\mathbf{2 . 0}$. High-penetration chevrons installed between the primary and tertiary streams (nozzle 040), chevrons facing (a) toward observer and (b) away from observer. Color indicates difference with baseline nozzle.

Comparing chevrons of the same penetration, but installed in the two different locations on the primary nozzle lip, requires comparing Figure 11b with Figure 13a. Figure 16 was prepared to allow side-by-side comparison of lowpenetration chevrons in the two different locations. When the low-penetration chevrons were positioned on the side of the observer, as was the case for both plots in Figure 16, the chevrons between the primary and flight streams (100B) produced more noise at high frequencies. This result corresponds to the greater shear of the 100B chevron location, where the high-speed/low speed velocity ratio was 450/102, compared with that of the 040B chevron location where the ratio was 450/330. More surprisingly, the chevrons on the high-shear location do not produce quite as much low-frequency noise reduction at the peak jet noise. 


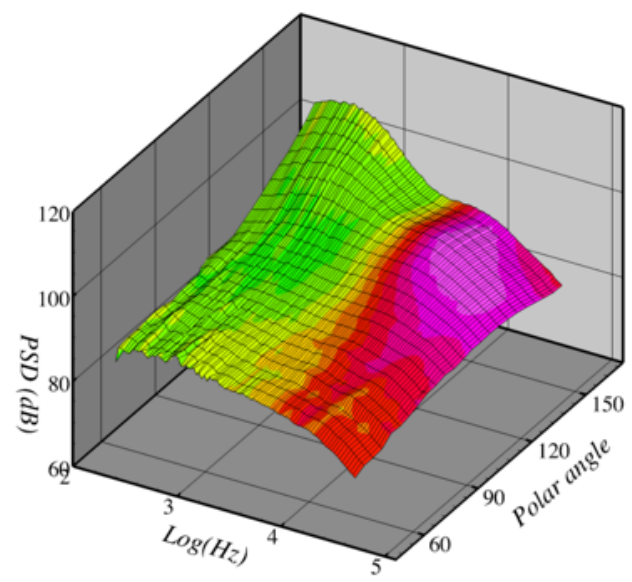

(a)

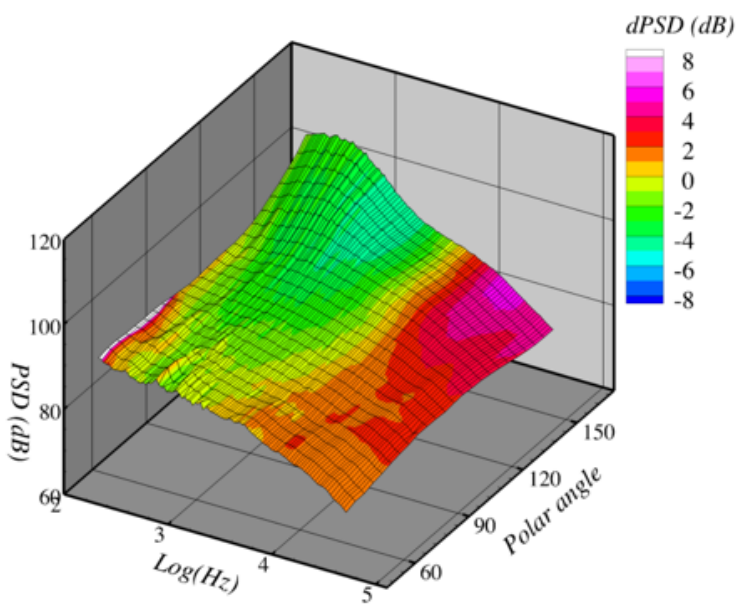

(b)

Figure 16. Spectral directivity of uninstalled chevron nozzles at $N P R_{p}=2.0$. Low-penetration chevrons installed (a) between the primary and flight streams (nozzle 100B), and (b) between primary and tertiary streams (nozzle 040). Chevrons facing toward observer. Color indicates difference with baseline nozzle.

Finally, consider the noise impact of having high-penetration chevrons in both azimuthal locations, creating configuration 240B. As shown in Figure 17, the combination of chevrons on all sides of the primary nozzle barely adds to the EPNL of the chevrons installed on each side individually. Spectrally, the penalties and benefits of chevrons were slightly amplified over that of the 040B nozzle.

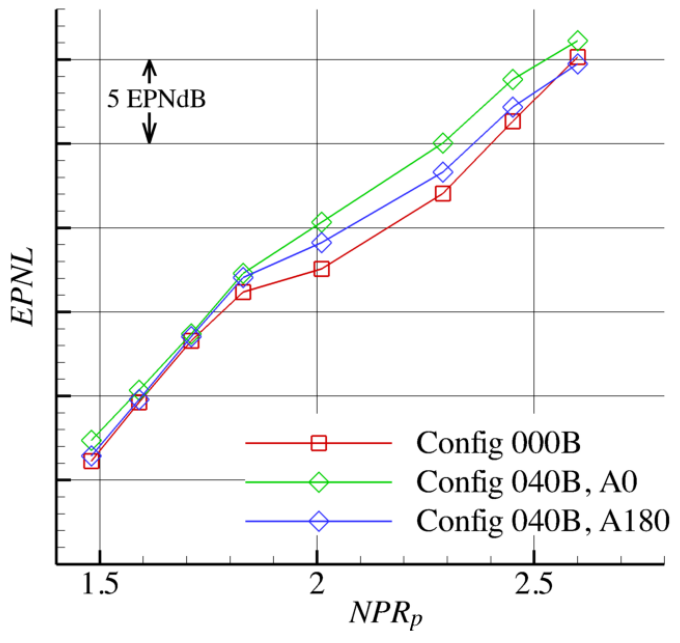

(a)

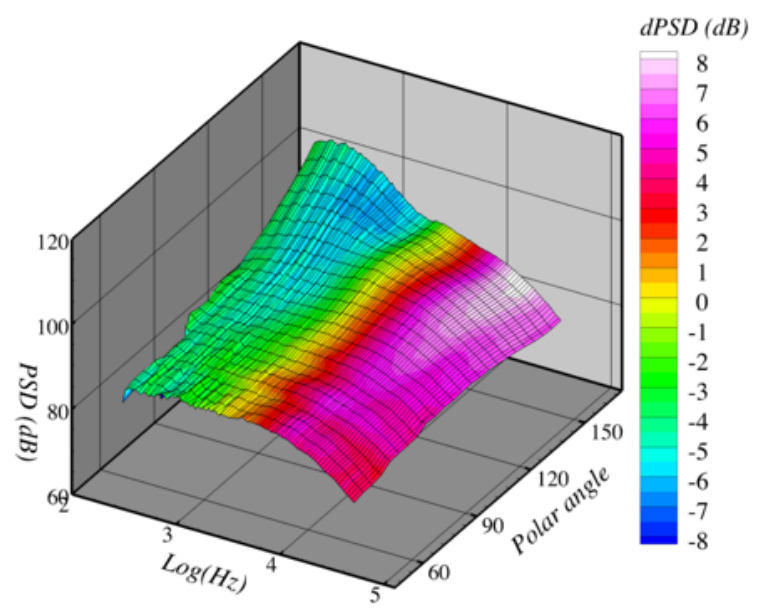

(b)

Figure 17. (a) Single-engine EPNL of uninstalled chevron nozzles 200B, 040B, 240B with high-penetration. (b) Spectral directivity of uninstalled 240B chevron nozzle with high-penetration chevrons on all sides of primary nozzle lip at $N P R_{r}=\mathbf{2 . 0}$. Color indicates difference with baseline nozzle.

Summarizing the results of the uninstalled nozzles, all the aggressive chevrons increased the high frequency noise over much of the power cycle, resulting in an increase in EPNL. This was as designed; the noise benefits should come from the installation on the top-side of the supersonic vehicle.

\section{Baseline nozzle, installed.}

In previous system studies, a $2 \mathrm{EPNdB}$ benefit has been estimated for the installation of the baseline nozzle, assuming significant shielding of the jet plume noise by the aft deck of the aircraft. In the testing to validate this assumption, measurements were made in two azimuthal angles corresponding to a flyover and a lateral observer. Results are compared below for the baseline nozzle, uninstalled and installed. 
The EPNL over the power cycle is given in Figure 18 for the baseline nozzle without the planform and with the planform at the two azimuthal planes, S0 and S60. The EPNL of the installed nozzle, both at S0 and S60, had the same general trend as the uninstalled nozzle, but with less of a dip at $N P R_{p}=2$. The nozzle being behind the tailfin rather than the full aft deck, the lateral observer (S60) had a little less shielding than the community observer (S0), but the reduction was roughly $2 \mathrm{EPNdB}$ for both, with more reduction being observed for $N P R_{p}$ less than 2 .

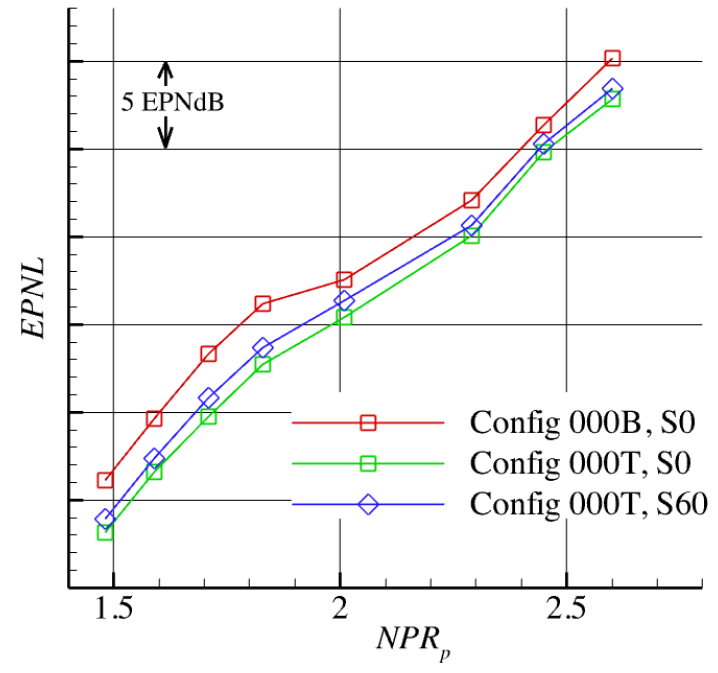

(a)

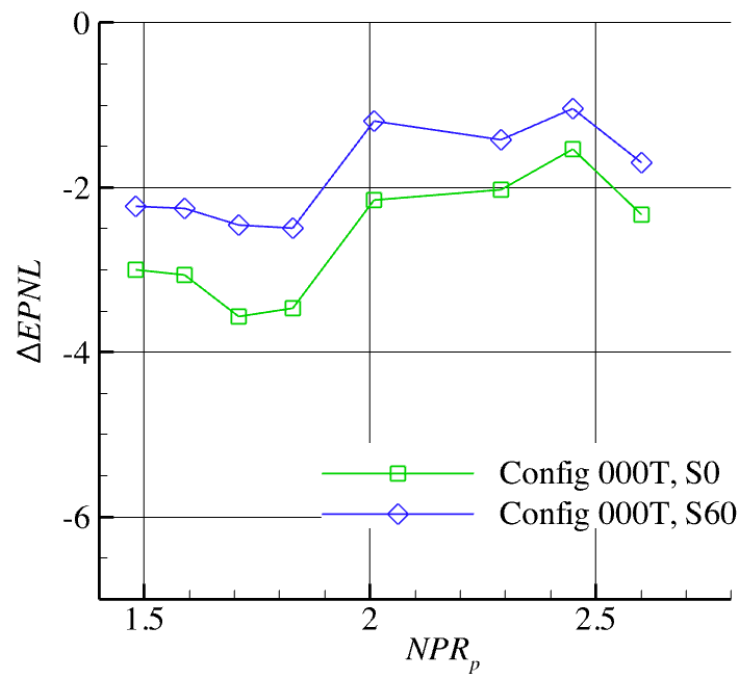

(b)

Figure 18. (a) Single-engine EPNL of baseline nozzle with and without ' $T$ ' planform, as measured for flyover (S0) and lateral (S60) observers. (b) difference in EPNL with installation, installed minus uninstalled.

Spectral directivities of the installed baseline nozzle are given in Figure 19. Three setpoints are shown: $N P R_{r}=1.8$, 2.0, and 2.3. These points bracket the most interesting behaviors noted in the EPNL and cover the pressure ratios most likely used on $\mathrm{N}+2$ aircraft. In the figure, the noise received by the community observer S0 are shown in the top row while the noise received by the lateral observer S60 is shown in the bottom row. The shapes of the surfaces are the PSD of the installed case and the coloring of the surface is given by the difference between the installed and uninstalled models.

In the plots a substantial portion of the high frequencies have been reduced by the installation as the planform shields these source located near the nozzle. That this was due to shielding and not due to modifications of the sound source is clear in the phased array results, shown in a companion paper". In addition, the high frequency humps associated with the subcritical broadband shock noise $\left(N P R_{p}=1.8\right)$ were reduced in the installed spectra. For the $\mathrm{S} 0$ observer, the region where the humps occur has reductions of as much as $8 \mathrm{~dB}$, as this source, locked to the plug, was well-shielded by the planform. The supercritical broadband shock noise $\left(N P R_{p}=2.3\right)$ was produced by shocks further downstream, and were not shielded more than the mixing noise.

Although it is not obvious in the shape of the surface, the coloration shows how there was an increase in low frequencies across upstream-to broadside angles when the nozzle was installed on a planform. This seems to correspond to the trailing edge dipole expected from the turbulent plume passing over the trailing edges of the planform. This increase was greater at the lower $N P R_{r}$, and may be slightly larger in amplitude for the S60 observer. Because the trailing edge dipole was rather directional, toward observers at right angles to the surface, there was not as much increase in noise at the aft angles. Also, keep in mind that unlike the shielding effect, the trailing edge dipole was an additional source, not a modification of a source in the uninstalled jet. 
(a)
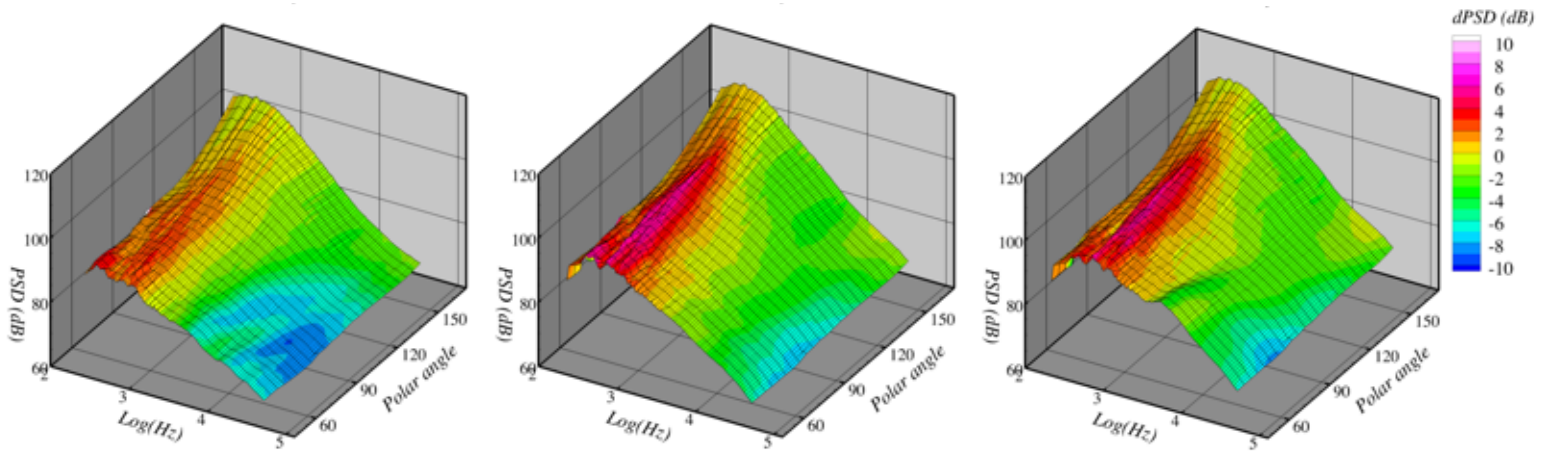

(b)

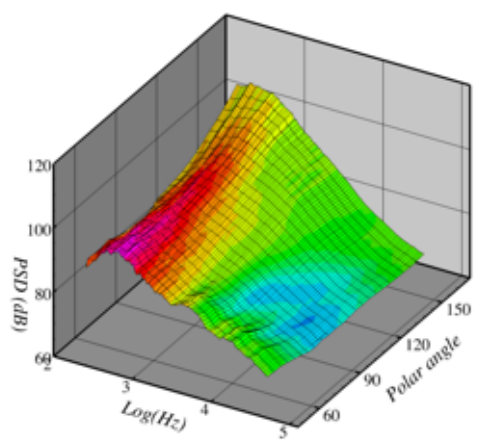

$N P R_{p}=1.8$

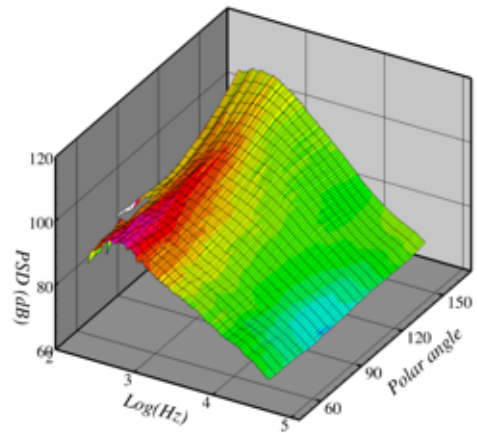

$N P R_{p}=2$

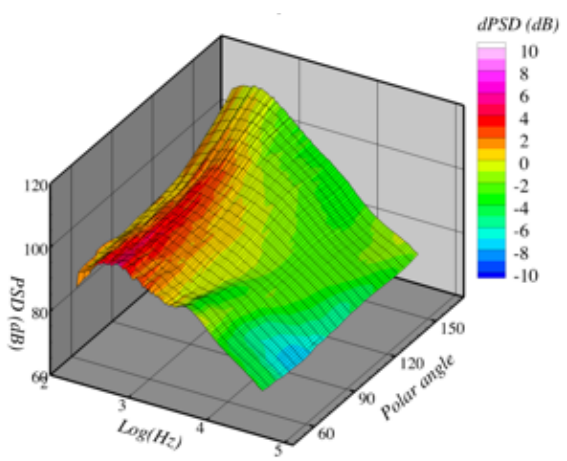

$N P R_{p}=2.3$

Figure 19. Spectral directivity of baseline nozzle installed on TMP17 planform at three engine conditions as observed by (a) community observer (S0), (b) sideline observer (S60). Color is difference between installed and isolated noise.

Two different planforms were tested, one with a low standoff (' $J$ ') and one with a high standoff (' $T$ '). Although the difference in geometry was significant, the difference in far-field noise for the baseline nozzle was small. Figure 20 shows the EPNL difference across the engine cycle for the two planforms, at both community and sideline observer points. The difference was generally less than $1 \mathrm{EPNdB}$. Spectrally, the differences were mostly insignificant, and hence not shown here. Particle image velocimetry measurements, presented in a companion paper ${ }^{\circ}$, showed that the standoff made only a slight difference on the baseline plume.

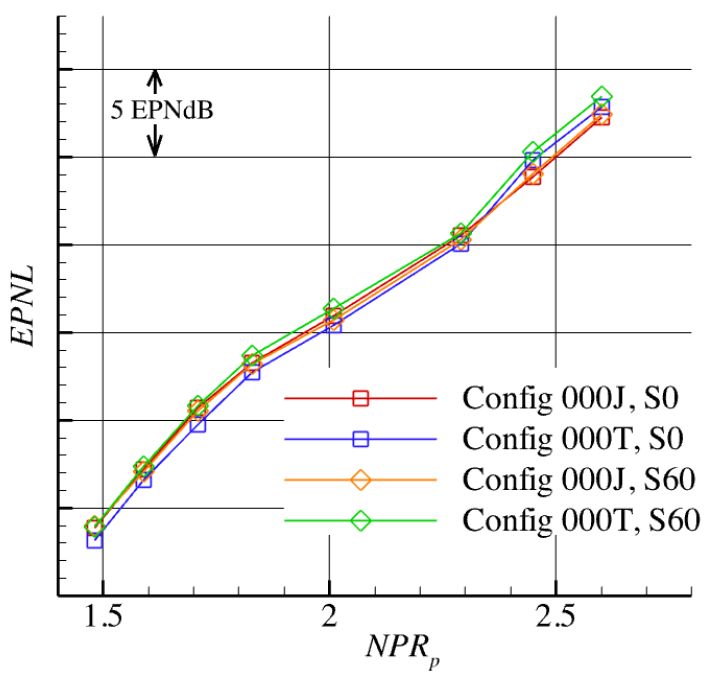

Figure 20. Single-engine EPNL of baseline nozzle with planforms low standoff (' $J$ ') and high standoff ('T'), for lateral (S60) and community (S0) observers. 


\section{Chevron nozzles, installed.}

While the EPNL of the uninstalled chevron nozzles was greater than that of the uninstalled baseline nozzle, the chevrons were created to be intentionally aggressive in the service of greater effectiveness when installed above the aft deck of the aircraft. In this location the high frequency noise produced by the aggressive mixing would be shielded, with the reduced downstream noise sources yielding a win-win for noise. Figure 21 shows how well this strategy worked in terms of EPNL for the flyover observer. EPNL for the engine cycle is shown for the four combinations of chevron penetration and location discussed above, but now installed on the high-standoff planform. The planform was attached to the tertiary stream side of the nozzle. The chevrons mounted on the side opposite the tertiary stream and the planform produced noise reductions only slight better than the installed baseline nozzle. The chevrons installed between the primary and tertiary streams fared better, producing reductions in EPNL of 4-5EPNdB.

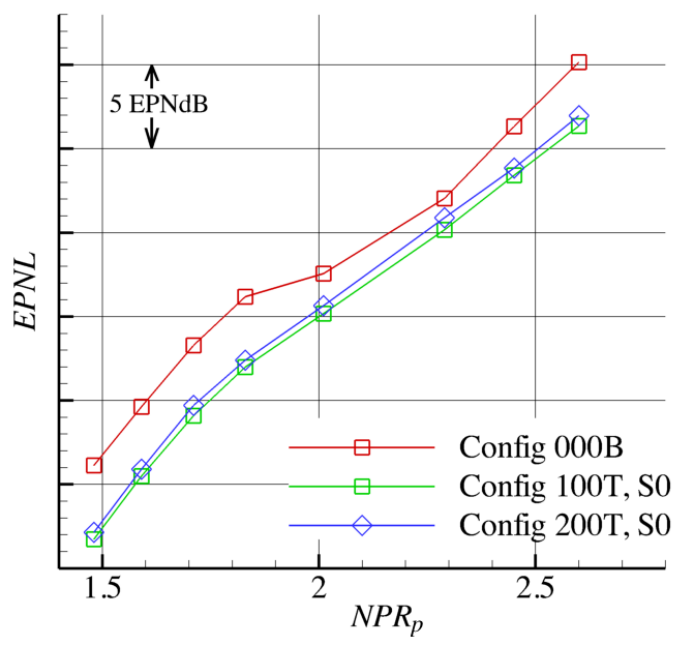

(a)

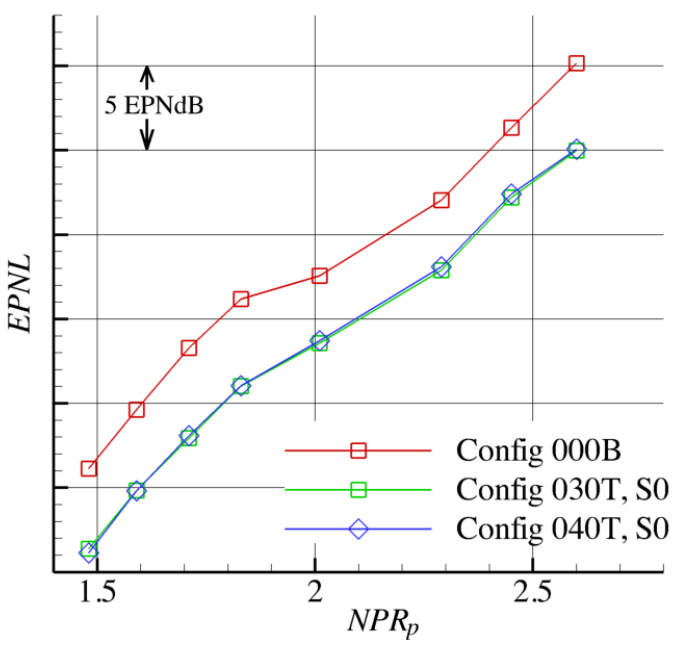

(b)

Figure 21. Single-engine EPNL of installed chevron nozzles with chevrons of varying penetration mounted on (a) primary-flight lip, and (b) primary-tertiary lip. Baseline uninstalled nozzle included for reference. Community observer orientation.

Predictions made in designing the test hardware indicated that the more aggressive chevron configurations would produce the lowest noise when installed on the vehicle. Specifically, the 240T configuration, with high-penetration chevrons all around the primary nozzle, was predicted to give the lowest EPNL, and the noise performance of this combination is the shown in Figure 22. For both observers, there was a substantial reduction, the S0 observer having roughly $1 \mathrm{~dB}$ more suppression from the chevron/installation combination than the S60 observer. However, the reductions were not as much as achieved by chevrons on one side only, the 040T configuration (Figure 21b). This was especially true for $N P R_{p}=2$ and greater. The question is why?

Spectral directivities for key cycle points, $N P R_{p}=1.8,2$, and 2.3, are given in Figure 23. The shape of the surfaces in the plots are the spectral directivity of the 240T configuration, while the colors are the difference between the noise of the installed chevron nozzle and the uninstalled baseline nozzle. As with the baseline nozzle, installation gave strong reductions in higher frequencies in spite of the increased noise of the chevrons. The low frequencies show reduction, especially at aft angles, just as the uninstalled chevron nozzles did. Recall that installation increased the low frequency noise of the baseline nozzle, partly because of the trailing edge dipole source created. With chevrons, the low frequency increases at forward angles were very small, indicating that the chevrons disrupted the trailing edge dipole source. And the chevrons strongly reduced the high frequency humps associated with the subcritical shock at the nozzle. The reason there isn't as much noise reduction at the $N P R_{p}=2$ points was because this shock noise was non-existent in the baseline nozzle at this point in the cycle.

Clearly, the aft deck was creating a significant amount of shielding. Figure 23b, showing the spectral directivity of the $240 \mathrm{~T}$ configuration as observed by the S60, or lateral, observer shows that the tailfin was not giving as much shielding as the aft deck. In far fore and aft angles the high frequency noise generated by the chevrons leaks around the tailfin" and increases the noise relative to the uninstalled baseline nozzle. 


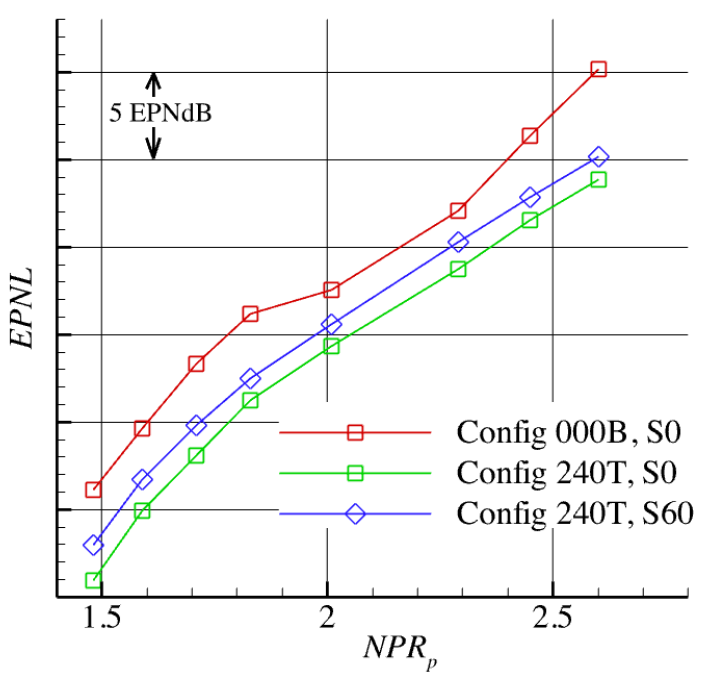

(a)

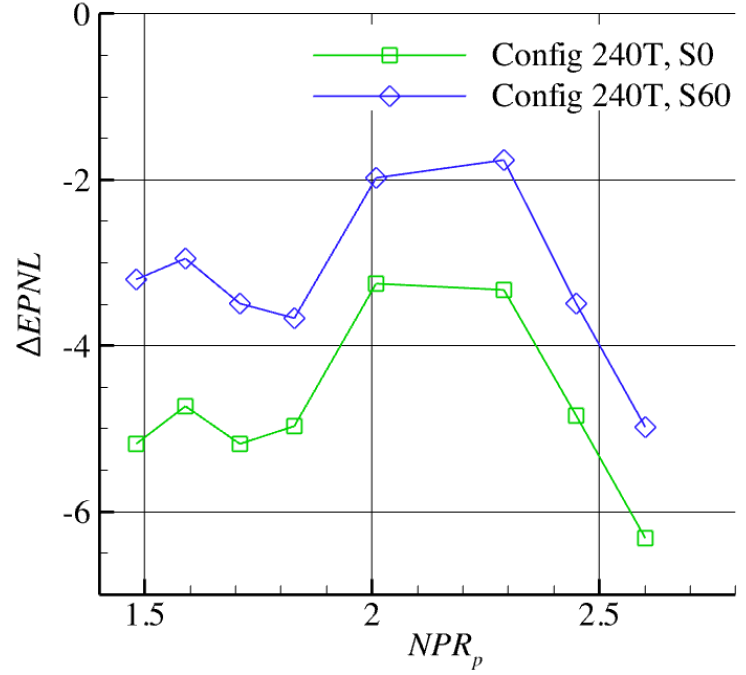

(b)

Figure 22. (a) Single-engine EPNL of baseline uninstalled nozzle, and most aggressive chevron design, lateral (S60) and community (S0) observers. (b) Difference in EPNL from uninstalled baseline.

(a)
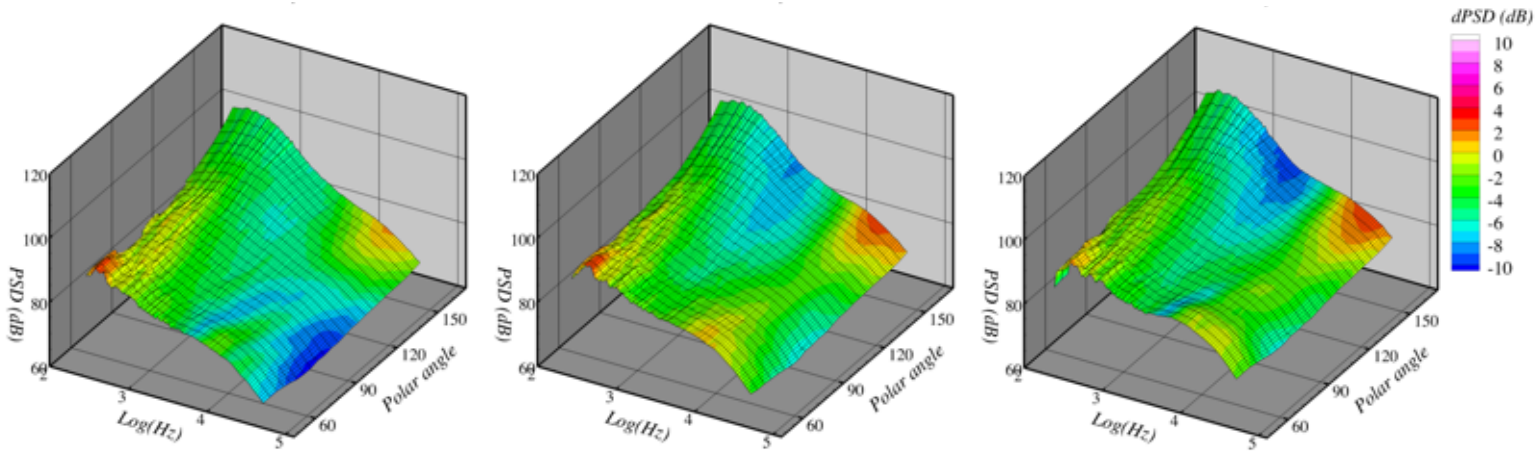

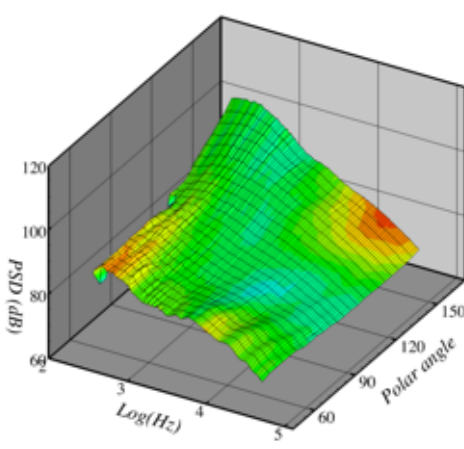

$N P R_{p}=1.8$

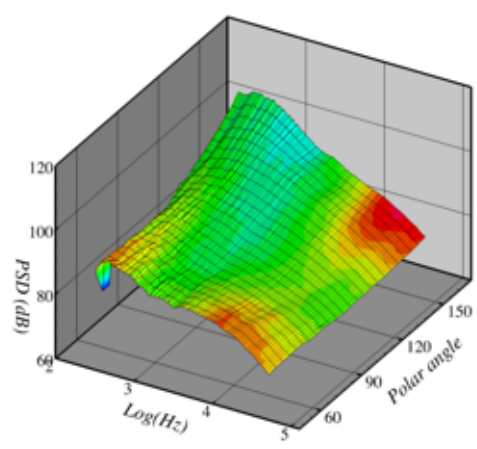

$N P R_{p}=2$

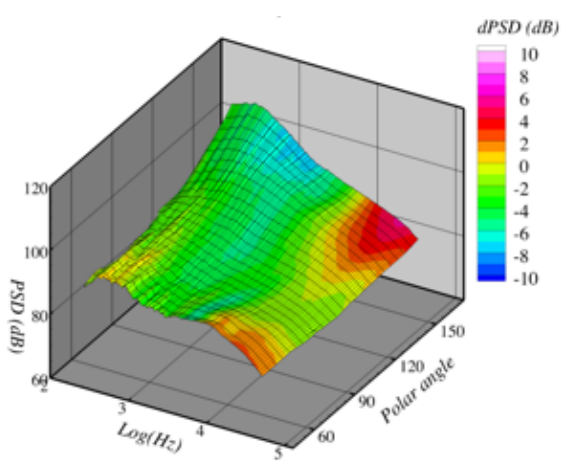

$N P R_{p}=2.3$

Figure 23. Spectral directivity of 240 chevron nozzle installed on TMP17 planform at three engine conditions as observed by (a) community observer (S0), (b) sideline observer (S60). Color is difference between 240 chevron nozzle installed and isolated baseline.

A more direct measure of how much shielding the aft deck produces is given in Figure 24, where the difference in spectral directivity between the installed and uninstalled 240 nozzle is given. At broadside polar angles, the aft deck produced a shielding benefit in excess of $10 \mathrm{~dB}$. This shielding effect dropped quickly aft far aft angles. Against this, the trailing edge dipole source produced by the planform added $4 \mathrm{~dB}$ to the low frequencies. 


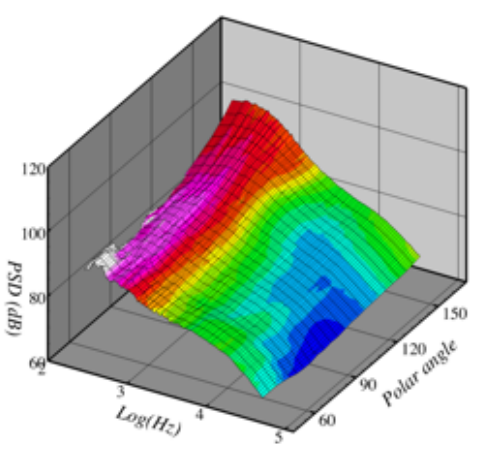

$N P R_{p}=1.8$

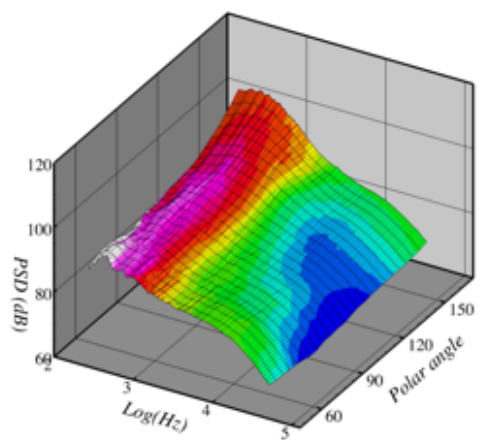

$N P R_{p}=2$

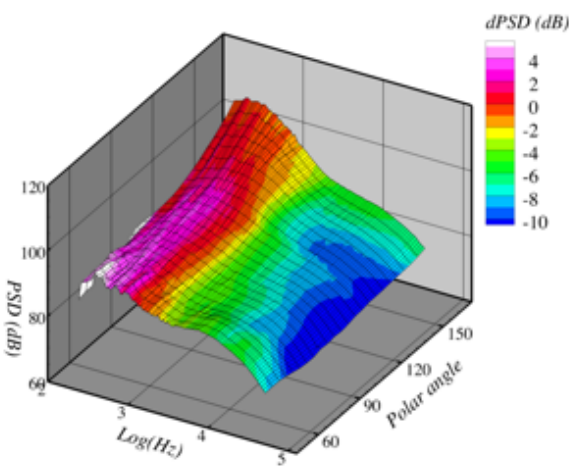

$N P R_{p}=2.3$

Figure 24. Spectral directivity of 240 chevron nozzle installed on TMP17 planform. Color is difference between 240 chevron nozzle installed and uninstalled. Community observer,

Because the 040T configuration produced even better noise reductions, a similar set of plots is given, comparing this configuration to the uninstalled baseline nozzle. Figure 25 shows the EPNL for the 040T configuration and the difference in EPNL between the 040T configuration and the baseline. The 040T configuration achieves 4-5EPNdB reduction across the cycle, with less benefit around $N P R_{r}=2$.

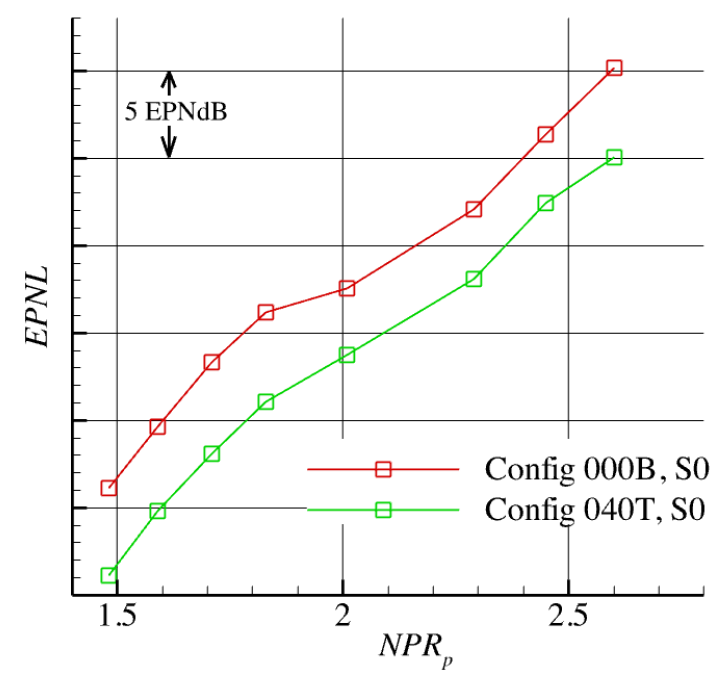

(a)

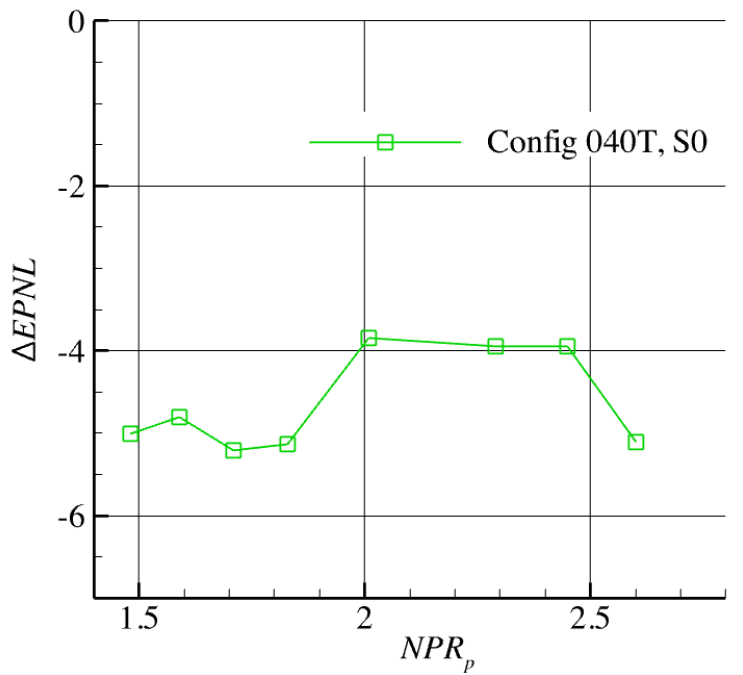

(b)

Figure 25. (a) Single-engine EPNL of baseline uninstalled nozzle, and most aggressive chevron design on primary-tertiary lip only, community (S0) observer. (b) Difference in EPNL from uninstalled baseline.

The spectral directivity plots of the 040T configuration relative to the uninstalled baseline nozzle (Figure 26) show that at $N P R_{r}=1.83$ a significant part of the reduction was coming from removing the high frequency humps caused by the subcritical shocks of the baseline nozzle. Above $N P R_{r}=2$, the broadband shock hump was still in evidence; this configuration does not remove them above $N P R_{r}=2$. There was a small amount of noise added at the low frequencies associated with the trailing edge dipole, but not much.

Comparing Figure 24 with Figure 26, the increase in high-frequency, aft noise was not as great in the 040T configuration as in the 240T configuration, nor was the reduction in the mid-frequency, aft noise. Comparing the 040T and $240 \mathrm{~T}$ spectral plots, it appears that the 240 T configuration produces a bit more high frequency noise than can be successfully shielded by the planform. The 040T design apparently produces as much low frequency benefit as the $240 \mathrm{~T}$ design, without as much high frequency penalty. 


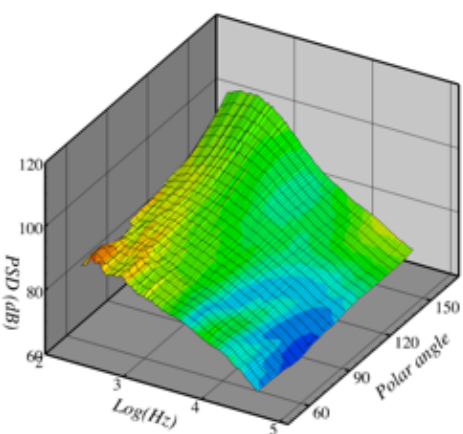

$N P R_{p}=1.8$

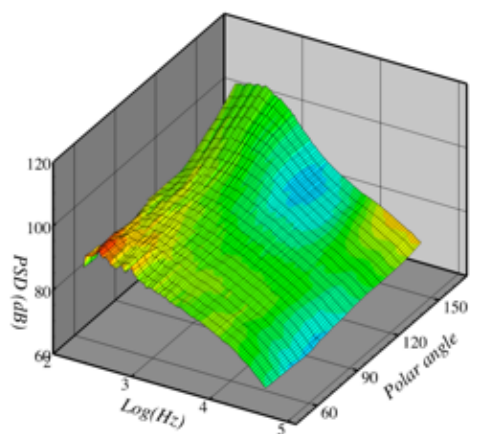

$N P R_{p}=2$

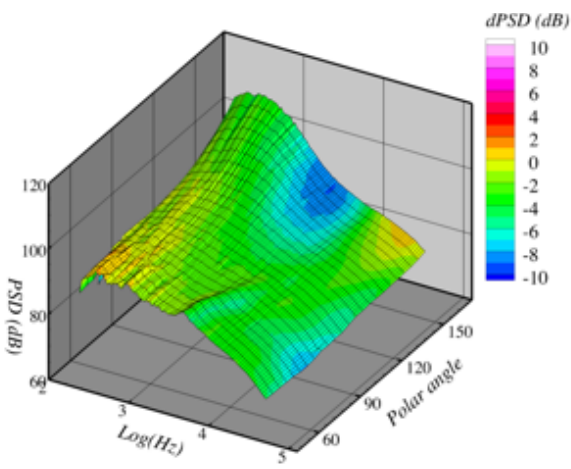

$N P R_{p}=2.3$

Figure 26. Spectral directivity of 040 Chevron nozzle installed on TMP17 planform. Color is difference between 040 chevron nozzle installed and isolated baseline. Community observer (S0).

\section{Summary}

A model-scale exhaust system was tested to validate low-noise exhaust system concepts and noise prediction methods. The concept: aggressive mixing enhancement devices, in this case chevrons, were applied to the nozzle to reduce the downstream, low-frequency noise sources. The high frequency noise sources these devices amplify were shielded by the aft deck of the airframe. The test articles were constructed to explore the chevron design parameters and the shielding produced by installation. Data were acquired for a series of nozzles with different chevron designs applied to different locations on the nozzle exit lips, both uninstalled and installed on a planform representing an N+2generation supersonic airliner. The tests measured far-field spectral directivity, noise source distributions using a translating phased array, and turbulent flow fields using particle image velocimetry; this report covers the far-field acoustics measurements. By installing the baseline propulsion system on the top of the vehicle's aft deck, some shielding of the jet mixing noise was demonstrated. Further reductions were created by applying the chevrons on the nozzle lips. The far-field acoustic data was processed to simulate the noise measured by a lateral observer in conventional certification testing, and the benefits of the chevrons and installation evaluated on an EPNL basis. Spectral directivities of the various configurations were compared to explain the EPNL values and to provide detailed validation data for the predictions methods being developed.

Installation of the engine on the top-side of the aft deck produced roughly 2EPNdB suppression for a sideline observer across most of the engine cycle for the baseline nozzle. Introducing chevrons on the uninstalled nozzle produced significant low-frequency benefits, but enhanced high frequency noise sources. However, when the chevron nozzles were installed on the top of the planform, the planform shielded much of the high frequency penalty, improving the suppression over the installed baseline nozzle, for a total of 4-5 EPNdB suppression for the best configuration. It was noted that the concept could be driven too far, as the high frequency sources of the most aggressive chevron configuration were insufficiently shielded, producing less EPNL reduction than a slightly less aggressive configuration. This study demonstrates the strategy for optimizing redistribution-shielding concept to minimize noise, and points to need for design tools to accurately predict the source distributions and shielding required to optimize this concept. Looking ahead, it will be critical that noise prediction tools be able to accurately assess the noise sources and their shielding, as configurations employing this concept are simultaneously optimized against other system goals such as sonic boom and cruise performance.

Companion papers ${ }^{10-12}$ will be presented showing particle image velocimetry and phased array measurements of the jet plumes for the various configurations studied here, along with computational studies of the nozzle designs. Insights from those measurements guided the discussion of the far-field results provided in this paper.

\section{Acknowledgements}

This work was supported by the Commercial Supersonic Technology Project of the Advanced Air Vehicles Program at NASA. The results were made possible by a highly skilled team of engineers and technicians at NASA Glenn's Aero-Acoustic Propulsion Lab and their dedication is greatly appreciated. 


\section{References}

${ }^{1}$ Morgenstern, J., Buonanno, M., Yao, J., Murugappan, M., Paliath, U., Cheung, L., Malcevic, I., Ramakrishnan, K., Pastouchenko, N., Wood, T., Martens, S., Viars, P., Tersmette, T., Lee, J., Simmons, R., Plybon, D., Alonso, J., Palacios, F., Lukaczyk, T., and Carrier, G., Advanced Concept Studies for Supersonic Commercial Transports Entering Service in the 2018-2020 Period Phase 2, NASA/CR-2016-218319, 2015. https://ntrs.nasa.gov/search.jsp?R=20150015837.

${ }^{2}$ Bridges, J. E., Brown, C. A., and Seidel, J. A., "NASA's Pursuit of Low-Noise Propulsion for Low-Boom Commercial Supersonic Vehicles," 2018 AIAA Aerospace Sciences Meeting, American Institute of Aeronautics and Astronautics, 2018. doi:10.2514/6.2018-0265.

3 Bridges, J. E., "Aeroacoustic Validation of Installed Low Noise Propulsion for NASA's N+2 Supersonic Airliner," 2018 AIAA Aerospace Sciences Meeting, American Institute of Aeronautics and Astronautics, 2018. doi:10.2514/6.2018-0009.

${ }^{4}$ Doty, M. J., Brooks, T. F., Burley, C. L., Bahr, C. J., and Pope, D. S., "Jet noise shielding provided by a hybrid wing body aircraft," International Journal of Aeroacoustics, vol. 17, Mar. 2018, pp. 135-158. doi:10.1177/1475472X17743659.

5 Papamoschou, D., and Mayoral, S., "Jet Noise Shielding for Advanced Hybrid Wing-Body Configuration," 49th AIAA Aerospace Sciences Meeting including the New Horizons Forum and Aerospace Exposition, American Institute of Aeronautics and Astronautics, 2011. doi:10.2514/6.2011-912.

${ }^{6}$ Bridges, J., and Brown, C., "Parametric Testing of Chevrons on Single Flow Hot Jets," 10th AIAA/CEAS Aeroacoustics Conference, American Institute of Aeronautics and Astronautics, 2004. doi:10.2514/6.2004-2824.

7 Zaman, K. B. M. Q., Bridges, J. E., and Huff, D. L., “Evolution from 'Tabs' to 'Chevron Technology' - A Review,” International Journal of Aeroacoustics, vol. 10, Oct. 2011, pp. 685-709. doi:10.1260/1475-472X.10.56.685.

${ }^{8}$ Thomas, R. H., Burley, C. L., and Olson, E. D., "Hybrid Wing Body Aircraft System Noise Assessment with Propulsion Airframe Aeroacoustic Experiments," International Journal of Aeroacoustics, vol. 11, Sep. 2012, pp. 369-409. doi:10.1260/1475-472X.11.3-4.369.

9 Mayoral, S., and Papamoschou, D., "Prediction of Jet Noise Shielding with Forward Flight Effects," 51 st AIAA Aerospace Sciences Meeting including the New Horizons Forum and Aerospace Exposition, American Institute of Aeronautics and Astronautics, 2018. doi:10.2514/6.2013-10.

${ }^{10}$ Bridges, J., and Wernet, M. P., "PIV measurements of a low-noise top-mounted propulsion installation for a supersonic airliner," AIAA SciTech 2019, American Institute of Aeronautics and Astronautics, 2019.

${ }^{11}$ Cluts, J. D., Bridges, J., and Podboy, G. G., "Translating Phased Array Measurements of Noise Source Locations of an Installed Jet," AIAA SciTech Forum 2019, American Institute of Aeronautics and Astronautics, 2019.

${ }^{12}$ Heberling, B., "Numerical Investigation of a Shielded Chevron Nozzle," 57th AIAA Aerospace Sciences Meeting, 2019.

${ }^{13}$ Ahuja, K. K. T., The free jet as a simulator of forward velocity effects on jet noise, NASA/CR-1978-3056, 1978. https://ntrs.nasa.gov/search.jsp?R=19790006702. 